\title{
San Francisco Bay Area Earthquake Simulations: A step toward a Standard Physical Earthquake Model
}

Steven N. Ward

Institute of Tectonics, University of California, Santa Cruz, CA 95064, USA

SUMMARY: Earthquakes in California's San Francisco Bay Area are likely to be more strongly affected by stress interaction than earthquakes in any other place in the world because of the region's closely spaced, sub-parallel distribution of faults. I believe therefore, that meaningful quantification of earthquake probability and hazard in the Bay Area can be made only with the guidance provided by physically-based and region-wide earthquake models that account for this interaction. This paper represents a first step in developing a Standard Physical Earthquake Model for the San Francisco Bay Area through realistic, 3000-year simulations of earthquakes on all of the area's major faults. These simulations demonstrate that a Standard Physical Earthquake Model is entirely feasible, they illustrate its application, and they blueprint its construction. A Standard Physical Earthquake Model provides the mechanism to integrate fully the diverse disciplines within the earthquake research community. As a platform for data utilization and verification, a physical earthquake model can employ directly any earthquake property that is measurable in the field or in the laboratory to tune and test its seismicity products. As a platform for probability forecasts, a physical earthquake model can supply rational estimates of every imaginable earthquake statistic while simultaneously satisfying all slip and earthquake rate constraints. As a platform for hazard analysis, a physical earthquake model can compute earthquake shaking intensity from first principles by convolving a full suite of rupture scenarios with site-specific dislocation Green's functions. Physical earthquake models have advanced greatly in the last decade. Simulations of earthquake generation and recurrence are now sufficiently credible that such calculations can begin to take substantial roles in scientific studies of earthquake probability and hazard.

\section{Introduction}

The United States Geological Survey is currently revising its 1990 probability estimates (WGCEP/ 90) for large earthquakes in the San Francisco Bay Area. Due to the region's closely spaced, sub-parallel distribution of faults (Figure 1), earthquakes of the San Francisco Bay are likely to be more strongly affected by fault stress interaction than earthquakes in any other place in the world. Given this, I believe that meaningful progress toward updating the WGCEP/90 probabilities can be made only with the guidance provided by physically-based and region-wide earth- 
quake simulations. As a first step toward realizing a Standard Physical Earthquake Model for the San Francisco Bay Area, this paper offers a set of seismicity simulations. These simulations demonstrate the feasibility of a Standard Physical Model and they blueprint its construction. The quasi-static earthquake simulations fielded herein resemble those originally developed for use in southern California (Ward, 1996), however the newer models incorporate several improvements in the theoretical formulation including:

1) Allowance for a finite speed of signal propagation $\left(v_{p}\right)$ while keeping within a quasi-static framework.

2) Association of a specific intra-seismic interval (dt) with each step in the rupture simulation.

3) Incorporation of fully localized fault friction.

4) Formation of explicit relationships among critical slip velocity, critical slip distance, and critical patch size for run-away failure in terms of $\mathrm{v}_{\mathrm{p}}$, $\mathrm{dt}$ and the difference between static and dynamic fault strengths.

\section{Theoretical Foundation}

Earthquakes interact in the sense that stresses shed from a fault during one event either advance or delay the occurrence of nearby earthquakes. Many researchers (Simpson and Reasenberg, 1994; Jaume and Sykes, 1996; Harris and Simpson, 1998) have applied this concept to the faults of the San Francisco Bay Area by mapping areas of stress enhancement or stress shadow caused by historical earthquakes. Stress interaction is a major component of a Standard Physical Earthquake Model and so it builds directly on these works. In fact, the theoretical and computational aspects of stress interaction employed here offer no significant advancement. This paper does however, include three primary extensions to previous efforts in this field:

- The timing and slip distribution of earthquakes are not specified by the user, but rather earthquakes occur spontaneously. Fault strength, fault friction law, and the existing state of stress solely determine the timing and extent of earthquake ruptures.

- Stress states are considered not only before and after earthquakes, but within each earthquake as well. This model generates detailed rupture histories from nucleation to healing.

- Applied interseismic stresses are not uniform. Instead, variable tectonic stresses drive each fault in the system at a velocity compatible with its estimated geological slip rate.

All seismicity simulations involve a balance between fault driving stresses and fault frictional resistance. I intro- 
duce below the quantities involved in this particular calculation. "KNOWN" in the description means that the quantity is specified at start time. Much of the notation is in vector form, the i-th component of each vector refers to conditions at the i-th fault element. Let:

$\mathbf{x}_{\mathrm{i}}$ be the center points of $\mathrm{N}$ small, planar fault elements of length $2 \mathrm{~b}_{\mathrm{i}}$ and down-dip width $2 \mathrm{w}_{\mathrm{i}}$ that comprise a fault network. (KNOWN)

$\mathbf{R}=\mathrm{R}_{\mathrm{ij}}\left(\mathbf{x}_{\mathrm{i}}, \mathbf{x}_{\mathrm{j}}\right)$ be the static Coulomb stress $\left[\mathrm{T}\left(\mathbf{x}_{\mathrm{i}}\right)=\tau\left(\mathbf{x}_{\mathrm{i}}\right)+\lambda \sigma\left(\mathbf{x}_{\mathrm{i}}\right)\right]$ induced at $\mathbf{x}_{\mathrm{i}}$ from a unit positive slip on the $\mathrm{j}$-th fault element. I reckon slip positive at $\mathbf{x}_{\mathrm{j}}$ in the same sense as the fault's geological motion, and shear stress $\tau\left(\mathbf{x}_{\mathrm{i}}\right)$ positive if its sense supports positive slip at $\mathbf{x}_{\mathrm{i}}$. Normal stress $\sigma$, is positive in tension and negative in compression. (KNOWN)

$\mathbf{T}_{\mathrm{o}}$ be the coulomb stress at $\mathbf{x}_{\mathrm{i}}$ at the start of the simulation. (KNOWN)

$\mathbf{T}_{\mathrm{p}}$ be the rate of coulomb stress induced at $\mathbf{x}_{\mathrm{i}}$ from plate tectonic driving forces. (KNOWN)

$\mathbf{v}_{\text {plate }}$ be the geological slip rate of the fault elements. (KNOWN)

$\mathbf{S}_{\mathrm{s}}$ and $\mathbf{S}_{\mathrm{d}}$ be the fixed static and dynamic strengths of the $\mathrm{N}$ fault elements. (KNOWN)

$\mathbf{u}(\mathrm{t})$ be the total slip on the $\mathrm{i}$-th fault element since the start of the simulation.

$\mathbf{v}(\mathrm{t})$ be slip velocity on the $\mathrm{i}$-th fault element at time $\mathrm{t}$.

$\mathbf{T}(\mathrm{t})$ be the Coulomb stress at $\mathbf{x}_{\mathrm{i}}$ at time $\mathrm{t}$.

and

$\mathbf{Q}(\mathrm{t})$ be the frictional strength of the fault at $\mathbf{x}_{\mathrm{i}}$ at time $\mathrm{t}$.

With this notation, the elements of the fault network at time $t$ suffer total Coulomb stress

$$
\mathbf{T}(\mathrm{t})=\mathbf{T}_{\mathrm{o}}+\mathrm{t} \mathbf{T}_{\mathrm{p}}+\mathbf{R u}(\mathrm{t}) .
$$

Plate tectonic forces drive the fault system at a rate

$$
\mathbf{T}_{\mathrm{p}}=-\mathbf{R} \mathbf{v}_{\text {plate }} .
$$

Because geological slip rate $\mathbf{v}_{\text {plate }}$ may not be constant over the fault network, and because the static response matrix $\mathbf{R}$, is a complex function for networks that include ends, steps, bends, and multiple interacting strands, $\mathbf{T}_{\mathrm{p}}$ may be wiggly with both positive and negative elements. With (2), (1) becomes 


$$
\mathbf{T}(\mathrm{t})=\mathbf{T}_{\mathrm{o}}+\mathbf{R}\left[\mathbf{u}(\mathrm{t})-\mathrm{t} \mathbf{v}_{\text {plate }}\right] .
$$

Obviously, so as long as the total fault slip $\mathbf{u}(\mathrm{t})$, keeps close pace with the plate tectonic value $\mathbf{t}_{\text {plate }}$, Coulomb stress (3) remains low. This sensible consequence in fact, motivated (2).

Fault frictional strength $\mathbf{Q}$ balances Coulomb stress (3) as

$$
\mathbf{T}(\mathrm{t})=\mathbf{T}_{\mathrm{o}}+\mathbf{R}\left[\mathbf{u}(\mathrm{t})-\mathrm{tv}_{\text {plate }}\right]=\mathbf{Q}\left(\mathbf{S}_{\mathrm{s}}, \mathbf{S}_{\mathrm{d}}, \mathbf{u}(\mathrm{t}), \mathbf{v}(\mathrm{t}), \mathbf{T}(\mathrm{t})\right)
$$

As defined above, $\mathbf{S}_{\mathrm{s}}$ and $\mathbf{S}_{\mathrm{d}}$ are the fixed static and dynamic strengths of the fault. They can however vary along strike. We see later that only the effective strength $\Delta \mathbf{S}$, the difference between $\mathbf{S}_{\mathrm{s}}$ and $\mathbf{S}_{\mathrm{d}}$, bears on earthquake generation, so for practical purposes $\mathbf{S}_{\mathrm{d}}$ can be taken to be zero. Fault frictional strength $\mathbf{Q}$ has many forms (e.g. Dieterich, 1992, 1994; Dieterich and Kilgore, 1996) and it may include other state parameters beyond those listed. In any case, if $\mathbf{u}(\mathrm{t})$ increasingly lags $t \mathbf{v}_{\text {plate }}, \mathbf{T}(\mathrm{t})$ becomes increasingly large and positive until on some fault elements

$$
\mathrm{T}_{\mathrm{i}}(\mathrm{t})>\mathrm{Q}_{\mathrm{i}}\left(\mathbf{S}_{\mathrm{s}}, \mathbf{S}_{\mathrm{d}}, \mathbf{u}(\mathrm{t}), \mathbf{v}(\mathrm{t}), \mathbf{T}(\mathrm{t})\right)
$$

When condition (5) happens, $\mathbf{u}(\mathrm{t})$ advances to $\mathbf{u}(\mathrm{t}+\mathrm{dt})$ to rebalance (4) -- i.e. an earthquake strikes.

Depending upon the specifics of $\mathbf{Q}$, various numerical recipes might advance $\mathbf{u}(\mathrm{t})$. I use the iterative scheme codified by $\operatorname{Ward}(1991,1996)$. This scheme reduces to finding a slip increment $\mathrm{du}(\mathrm{t}) \geq \mathbf{0}$ such that

$$
\mathrm{du}_{\mathrm{i}}(\mathrm{t})=0 \text { if } \mathrm{dT}_{\mathrm{i}}(\mathrm{t})=0
$$

and that gives

$$
\mathrm{R}_{\mathrm{ij}} \mathrm{du}_{\mathrm{j}}(\mathrm{t})=-\mathrm{dT}_{\mathrm{i}}(\mathrm{t})
$$

at those points where $d T_{i}(t) \neq 0$. $d \mathbf{T}(t)$ is the stress excess

$$
\mathrm{d} \mathbf{T}(\mathrm{t})=\max \left[0, \mathbf{T}(\mathrm{t})-\mathbf{Q}\left(\mathbf{S}_{\mathrm{s}}, \mathbf{S}_{\mathrm{d}}, \mathbf{u}(\mathrm{t}), \mathbf{v}(\mathrm{t}), \mathbf{T}(\mathrm{t})\right)\right]
$$

In words, $d \mathbf{u}(\mathrm{t})$ is that non-negative slip, existing only over the domain where current stress exceeds the current frictional strength, that causes the stress excess to vanish over that domain. The iterative procedure involves repeated multiplication by matrices $\mathbf{R}$ and $\mathbf{R}^{-1}$ as

$$
\mathbf{R}^{-1} \delta \mathbf{T}^{(\mathrm{n})}(\mathrm{t})=\delta \mathbf{u}^{(\mathrm{n})}
$$

and 


$$
\delta \mathbf{T}^{(\mathrm{n}+1)}=\lim \left\{\mathrm{d} \mathbf{T}(\mathrm{t})-\mathbf{R} \lim \left[\operatorname{pos}\left(\sum_{k=1}^{n} \delta \mathbf{u}^{(\mathrm{k})}(\mathrm{t})\right)\right]\right\}
$$

starting with $\delta \mathbf{T}^{(1)}(\mathrm{t})=\mathrm{d} \mathbf{T}(\mathrm{t})$. The $\operatorname{pos}\{\mathbf{z}\}$ function zeros all negative $\mathrm{z}_{\mathrm{i}}$. The $\lim \{\mathbf{z}\}$ function zeros all $\mathrm{z}_{\mathrm{i}}$ where $\mathrm{dT}_{\mathrm{i}}(\mathrm{t})=0$. Note that the matrix $\mathbf{R}^{-1}$ needs to be calculated only once for any fault network. When $\delta \mathbf{T}^{(\mathrm{n}+1)}$ falls sufficiently close to zero, $\lim \left[\operatorname{pos}\left\{\Sigma \delta \mathbf{u}^{(\mathrm{n})}(\mathrm{t})\right\}\right]=\mathrm{du}(\mathrm{t})$ solves the problem. Letting $\mathrm{u}(\mathrm{t}+\mathrm{dt})=\mathrm{u}(\mathrm{t})+\mathrm{du}(\mathrm{t}),(4)$ becomes

$$
\mathbf{T}(\mathrm{t}+\mathrm{dt})=\mathbf{T}_{\mathrm{o}}+\mathbf{R}\left[\mathbf{u}(\mathrm{t}+\mathrm{dt})-(\mathrm{t}+\mathrm{dt}) \mathbf{v}_{\mathbf{p}}\right]=\mathbf{Q}\left(\mathbf{S}_{\mathrm{s}}, \mathbf{S}_{\mathrm{d}}, \mathbf{u}(\mathrm{t}+\mathrm{dt}), \mathbf{v}(\mathrm{t}+\mathrm{dt}), \mathbf{T}(\mathrm{t}+\mathrm{dt})\right)
$$

If the new stress $\mathbf{T}(\mathrm{t}+\mathrm{dt})$, anywhere exceeds the new frictional strength, the process repeats. In each passage of the loop from (4) to (9), ruptures expand, heal, and new ones might nucleate. When (9) is satisfied to a desired limit, the earthquake stops. At this point, time advances by interseismic interval $\Delta \mathrm{T}$ and (4) would be re-examined for condition (5). Intra-seismic interval $\mathrm{dt}$ is on the order of seconds, but interseismic interval $\Delta \mathrm{T}$ can be months or years as needed to expedite the formation of a long seismicity catalog.

\subsection{Passing to a Finite Signal Speed}

Traditional quasi-static solutions sometimes face criticism on the basis of "infinite signal speed". That is, point $\mathbf{x}_{j}$ feels instantaneously the Coulomb stress $T_{j}(t+d t)(9)$ from slip increment $d_{i}(t)$ regardless of the distance between $\mathbf{x}_{\mathrm{i}}$ and $\mathbf{x}_{\mathrm{j}}$ or the selection of $\mathrm{dt}$. I incorporate a finite speed of signal propagation $\mathrm{v}_{\mathrm{p}}$, into the synthetic seismicity models while holding within a quasi-static framework by passing the $\mathbf{R u}(\mathrm{t}+\mathrm{dt})$ term in (9) to

$$
\mathbf{R u}(\mathrm{t}+\mathrm{dt}) \Rightarrow \mathbf{R}^{(2)} \mathrm{d} \mathbf{u}(\mathrm{t})+\mathbf{R}^{(3)} \mathrm{d} \mathbf{u}(\mathrm{t}-\mathrm{dt})+\mathbf{R}^{(4)} \mathrm{d} \mathbf{u}(\mathrm{t}-2 \mathrm{dt})+\mathbf{R}^{(5)} \mathrm{d} \mathbf{u}(\mathrm{t}-3 \mathrm{dt})+------+\mathbf{R} \mathbf{u}(\mathrm{t}-\mathrm{Mdt})
$$

where $\mathrm{R}_{\mathrm{ij}}^{(\mathrm{n})}=\mathrm{R}_{\mathrm{ij}} \mathrm{H}\left(\mathrm{nv}_{\mathrm{p}} \mathrm{dt}-\left|\mathbf{x}_{\mathrm{i}}-\mathbf{x}_{\mathrm{j}}\right|\right)$ and $\mathrm{H}(\mathrm{a})$ is the Heaviside step function. $\mathbf{R}^{(\mathrm{n})}$ includes only those terms in the static response matrix that refer to point pairs lying within distance $n v_{p} d t$. For small $n, \mathbf{R}^{(n)}$ tends to be tightly banded. With increasing $\mathrm{n}$, more and more matrix elements come to play. If $\mathrm{D}_{\max }$ is the maximum separation of any two points in the fault system, then for $\mathrm{n}>\mathrm{M}=\mathrm{D}_{\max } / \mathrm{v}_{\mathrm{p}} \mathrm{dt}, \mathbf{R}^{(\mathrm{n})}=\mathbf{R}$. Thus, the final term in (10) multiplies the total slip $\mathbf{u}(\mathrm{t}-$ Mdt), not a slip increment du. Passage to finite signal speed also means that matrices $\mathbf{R}^{(1)}$ and $\left[\mathbf{R}^{(1)}\right]^{-1}$ replace $\mathbf{R}$ and $\mathbf{R}^{-1}$ in the iteration scheme (8.1) and (8.2). Even so, inverse matrix $\left[\mathbf{R}^{(1)}\right]^{-1}$ need be calculated only once.

Modification (10) causes all of the time dependent elastic signals in these simulations to be causal, and to propagate at speeds no greater than $\mathrm{v}_{\mathrm{p}}$. Causality and finite signal speed are two fundamental features of "full" calculations that include the inertial term $\rho \partial^{2} u(t) / \partial^{2} t$ in the equations of motion. I suggest that reproducing these features 
through (10) is a proper step. In the whole space used here, point-dislocation stresses and displacements from full calculations vanish before the $\mathrm{P}$-wave arrival and equal their static values after the $\mathrm{S}$-wave arrival. If $\mathrm{v}_{\mathrm{p}}$ equals the $\mathrm{P}$ wave velocity, then modification (10) reproduces these circumstances as well. Only in the interval between the P and S-wave arrivals do modified quasi-static methods sacrifice accurate accounting of the wavefield. Of course, the Earth is not a whole space, nor are the elastic fields therein quasi-static. My attempts here intend to mimic full 3-D dynamic calculations, not replace them. Future versions of the Standard Physical Model should relax current restrictions. Still, in return for sacrificing some rigor, modified quasi-static methods do make for far less computational effort than full 3-D dynamic calculations because the time delayed quasi-static response is so easily found. If desired, because the simulation determines fault slip $\mathrm{u}\left(\mathbf{x}_{\mathrm{i}}, \mathrm{t}\right)$ for all times and fault elements, synthetic seismograms $u_{\text {seis }}(\mathbf{p}, t)$ that do include full wave effects can be computed at any position $\mathbf{p}$, on or off of the faults, by convolving $\mathrm{u}\left(\mathbf{x}_{\mathrm{i}}, \mathrm{t}\right)$ with the appropriate dislocation Green's function

$$
\mathrm{u}_{\text {seis }}(\mathbf{p}, \mathrm{t})=\mathrm{G}\left(\mathbf{p}, \mathbf{x}_{\mathrm{i}}, \mathrm{t}\right) * \mathrm{u}\left(\mathbf{x}_{\mathrm{i}}, \mathrm{t}\right)
$$

\subsection{Fault Frictional Strength}

Any appropriate friction law can be employed in versions of a Standard Physical Model. Below I introduce a simple two-parameter law that adequately illustrates the vision. Initially, let fault frictional strength be defined as follows:

if $\mathrm{T}_{\mathrm{i}}(\mathrm{t}) \leq\left(\mathrm{S}_{\mathrm{s}}\right)_{\mathrm{i}}$ then

$$
\mathrm{Q}_{\mathrm{i}}\left(\mathbf{S}_{\mathrm{s}}, \mathbf{S}_{\mathrm{d}}, \mathbf{u}(\mathrm{t}), \mathbf{v}(\mathrm{t}), \mathbf{T}(\mathrm{t})\right)=\mathrm{T}_{\mathrm{i}}(\mathrm{t})
$$

if $\mathrm{T}_{\mathrm{i}}(\mathrm{t})>\left(\mathrm{S}_{\mathrm{s}}\right)_{\mathrm{i}}$ and $\mathrm{v}_{\mathrm{i}}(\mathrm{t})=0$ then

$$
\mathrm{Q}_{\mathrm{i}}\left(\mathbf{S}_{\mathrm{s}}, \mathbf{S}_{\mathrm{d}}, \mathbf{u}(\mathrm{t}), \mathbf{v}(\mathrm{t}), \mathbf{T}(\mathrm{t})\right)=\left(\mathrm{S}_{\mathrm{s}}\right)_{\mathrm{i}}
$$

if $\mathrm{v}_{\mathrm{i}}(\mathrm{t}) \neq 0$ then

$$
\mathrm{Q}_{\mathrm{i}}\left(\mathbf{S}_{\mathrm{s}}, \mathbf{S}_{\mathrm{d}}, \mathbf{u}(\mathrm{t}), \mathbf{v}(\mathrm{t}), \mathbf{T}(\mathrm{t})\right)=\max \left[\left(\mathrm{S}_{\mathrm{d}}\right)_{\mathrm{i}},\left(\mathrm{S}_{\mathrm{s}}\right)_{\mathrm{i}}-\Delta \mathrm{S}_{\mathrm{i}} \mathrm{v}_{\mathrm{i}}(\mathrm{t}) / \mathrm{v}_{\mathrm{c}}\right](12.3)
$$

where again, $\Delta \mathrm{S}_{\mathrm{i}}=\left(\mathrm{S}_{\mathrm{s}}\right)_{\mathrm{i}}-\left(\mathrm{S}_{\mathrm{d}}\right)_{\mathrm{i}}$ labels effective strength. Equation (12.3) describes velocity weakening -- i.e. fault strength drops linearly with slip velocity from the static strength $\left(\mathrm{S}_{\mathrm{s}}\right)_{\mathrm{i}}$ at $\mathrm{v}_{\mathrm{i}}(\mathrm{t})=0$ to the dynamic strength $\left(\mathrm{S}_{\mathrm{d}}\right)_{\mathrm{i}}$ at critical slip velocity $\mathrm{v}_{\mathrm{i}}(\mathrm{t})=\mathrm{v}_{\mathrm{c}}$. Fault friction (12) is fully localized in that it depends only on the values of velocity, slip (introduced in equation 21), and Coulomb stress at the single point in question. 


\section{Earthquake Nucleation Conditions:}

Suppose that at $\mathrm{t}=0$ a resting fault possesses a small stress excess

$$
\mathrm{dT}(0)=\mathrm{T}(0)-\mathrm{Q}(0)=\mathrm{T}(0)-\mathrm{S}_{\mathrm{s}}=\varepsilon
$$

across a patch of length $\mathrm{L}_{\mathrm{c}}$. Under the conditions of two-dimensional plane stress, release of any uniform stress excess dT on a patch of length $\mathrm{L}_{\mathrm{c}}$ induces a peak slip

$$
\mathrm{du}=\mathrm{dTL}_{\mathrm{c}} / \mu(1+v)
$$

Here, $\mu$ and $v$ symbolize rigidity and Poisson's ratio. Due to the finite speed of signal propagation and the finite size of the patch, slip du develops over interval dt

$$
\mathrm{dt}=2 \mathrm{~L}_{\mathrm{c}} / \mathrm{v}_{\mathrm{p}}
$$

the time needed for the signal to propagate from one end of the patch and return. From (13) and (14), the slip velocity on the patch at $\mathrm{t}=\mathrm{dt}$ is

$$
\mathrm{v}(\mathrm{dt})=\mathrm{du} / \mathrm{dt}=\mathrm{dT}(0) \mathrm{L}_{\mathrm{c}} / \mu(1+v) \mathrm{dt}=\varepsilon \mathrm{L}_{\mathrm{c}} / \mu(1+v) \mathrm{dt}(16)
$$

The new stress on the patch equals the initial stress less the stress excess removed by the slip,

$$
\mathrm{T}(\mathrm{dt})=\mathrm{T}(0)-\mathrm{dT}(0)=\left(\mathrm{S}_{\mathrm{s}}+\varepsilon\right)-\varepsilon=\mathrm{S}_{\mathrm{s}}
$$

At $\mathrm{t}=\mathrm{dt}$, the fault has velocity $\mathrm{v}(\mathrm{dt})$, so fault strength weakens to

$$
\mathrm{Q}(\mathrm{dt})=\mathrm{S}_{\mathrm{s}}-\Delta \mathrm{Sv}(\mathrm{dt}) / \mathrm{v}_{\mathrm{c}}
$$

by virtue of (12.3). This strength change generates a new stress excess of

$$
\mathrm{dT}(\mathrm{dt})=\mathrm{T}(\mathrm{dt})-\mathrm{Q}(\mathrm{dt})=\Delta \mathrm{Sv}(\mathrm{dt}) / \mathrm{v}_{\mathrm{c}}
$$

that is removed over time dt by slip

$$
\mathrm{du}(2 \mathrm{dt})=\left[\Delta \mathrm{Sv}(\mathrm{dt}) / \mathrm{v}_{\mathrm{c}}\right] \mathrm{L}_{\mathrm{c}} / \mu(1+v)
$$

The slip velocity at $\mathrm{t}=2 \mathrm{dt}$

$$
\mathrm{v}(2 \mathrm{dt})=\mathrm{du}(2 \mathrm{dt}) / \mathrm{dt}=\left[\Delta \mathrm{SL}_{\mathrm{c}} / \mu(1+\mathrm{v}) \mathrm{v}_{\mathrm{c}} \mathrm{dt}\right] \mathrm{v}(\mathrm{dt})
$$

causes fault strength to fall still further to

$$
\mathrm{Q}(2 \mathrm{dt})=\mathrm{S}_{\mathrm{s}}-\Delta \mathrm{Sv}(2 \mathrm{dt}) / \mathrm{v}_{\mathrm{c}}
$$

The stress excess at $\mathrm{t}=2 \mathrm{dt}$

$$
\mathrm{dT}(2 \mathrm{dt})=\mathrm{Q}(2 \mathrm{dt})-\mathrm{Q}(\mathrm{dt})
$$

induces a new slip velocity of

$$
\mathrm{v}(3 \mathrm{dt})=\left[\mathrm{L}_{\mathrm{c}} / \mu(1+v) \mathrm{dt}\right][\mathrm{Q}(2 \mathrm{dt})-\mathrm{Q}(\mathrm{dt})]=\left[\Delta \mathrm{SL}_{\mathrm{c}} / \mu(1+\mathrm{v}) \mathrm{v}_{\mathrm{c}} \mathrm{dt}\right][\mathrm{v}(2 \mathrm{dt})-\mathrm{v}(\mathrm{dt})]
$$


etc. After $\mathrm{n}$ steps, the patch has a slip velocity of

$$
\mathrm{v}(\mathrm{ndt})=\left[\mathrm{L}_{\mathrm{c}} / \mu(1+\mathrm{v}) \mathrm{dt}\right][\mathrm{Q}(\mathrm{ndt}-\mathrm{dt})-\mathrm{Q}(\mathrm{ndt}-2 \mathrm{dt})]=\left[\Delta \mathrm{SL}_{\mathrm{c}} / \mu(1+\mathrm{v}) \mathrm{v}_{\mathrm{c}} \mathrm{dt}\right][\mathrm{v}(\mathrm{ndt}-\mathrm{dt})-\mathrm{v}(\mathrm{ndt}-2 \mathrm{dt})]
$$

Slip velocity at $\mathrm{t}=\mathrm{ndt}$ is thus proportional to the change in slip velocity delayed by $\mathrm{dt}$, the time (15) it takes for the signal to traverse a patch of size $\mathrm{L}_{\mathrm{c}}$. This delay brings some stability to velocity weakening law (12.3). A little experimentation reveals that (17) increases exponentially to infinity for any initial velocity $\mathrm{v}(\mathrm{dt})$ (i.e. any initial stress excess $\varepsilon$ ) only if the first term in brackets equals or exceeds 4 . Thus, run-away earthquake nucleation occurs when

$$
4=\Delta \mathrm{SL}_{\mathrm{c}} / \mu(1+v) \mathrm{v}_{\mathrm{c}} \mathrm{dt}
$$

or from (15)

$$
\mathrm{v}_{\mathrm{c}}=\Delta \mathrm{SL}_{\mathrm{c}} / 4 \mu(1+v) \mathrm{dt}=\Delta \mathrm{Sv}_{\mathrm{p}} / 8 \mu(1+v)
$$

The critical slip velocity that appears in fault friction law (12.3) thus relates simply to the limiting signal speed and the effective strength $\Delta \mathrm{S}=\mathrm{S}_{\mathrm{s}}-\mathrm{S}_{\mathrm{d}}$ available to power earthquake slip. Additionally the critical patch size $\mathrm{L}_{\mathrm{c}}$ through (15), defines the dt needed in (9) and (10).

Figure 2 plots slip velocity versus time computed from (17) for an $\varepsilon$ stress excess applied over patches of various sizes. A small stress excess parents a run-away instability only if it spans minimum patch size $\mathrm{L}_{\mathrm{c}}$. Earthquakes do occur when an $\varepsilon$ stress excess exists over a smaller region, however, the stress drop will be partial and slip will be short lived. Given the initial velocity perturbation (16)

$$
\mathrm{v}(\mathrm{dt})=(4 \varepsilon / \Delta \mathrm{S}) \mathrm{v}_{\mathrm{c}}
$$

on a patch of dimension $L_{c}$, a time-to-failure $T_{c}$, can be defined as that time at which $v\left(T_{c}\right)=v_{c}$. The locations of the squares in Figure 2 supply

$$
\begin{array}{cccccccc}
(4 \varepsilon / \Delta \mathrm{S}): & 10^{-3} & 10^{-4} & 10^{-5} & 10^{-6} & 10^{-7} & 10^{-8} & (19) \\
\mathrm{T}_{\mathrm{c}}: & 8 & 11 & 14 & 17 & 20 & 23 \times 2 \mathrm{~L}_{\mathrm{c}} / \mathrm{v}_{\mathrm{p}}
\end{array}
$$

Smaller initial perturbations naturally take longer to reach instability. Lastly a critical slip distance is

$$
\mathrm{d}_{\mathrm{c}}=\mathrm{v}_{\mathrm{c}} \mathrm{dt}=\Delta \mathrm{SL}_{\mathrm{c}} / 4 \mu(1+\mathrm{v})
$$

Faults with a lengthy time-to-failure tend to resist triggering by propagating dynamic pulses. Although transient pulses may induce stresses that exceed the local fault strength, the excess may not persist long enough over the whole patch to trigger a run-away instability. 
Relations (18) to (20) are straightforward consequences of velocity weakening and the finite time dt, required for slip velocity on a patch of dimension $L_{c}$ to respond to changes in fault friction. The factor $L_{c} / \mu(1+v)$ stems from the two-dimensional, plane stress formulation (14) that relates stress change to slip on a patch. Three-dimensional dislocations have different scale factors in that relationship, but the logic leading to (18), (19), and (20) will be the same.

For example, let $\mu=3 \times 10^{10} \mathrm{~Pa}, v=0.25, \mathrm{v}_{\mathrm{p}}=6 \mathrm{~km} / \mathrm{s}, \Delta \mathrm{S}=20$ bars, $\varepsilon=0.005$ bars and $\mathrm{L}_{\mathrm{c}}=6 \mathrm{~km}$; then, $\mathrm{v}_{\mathrm{c}}=4 \mathrm{~cm} / \mathrm{s}, \mathrm{dt}=2$ $\mathrm{s}, \mathrm{T}_{\mathrm{c}}=16 \mathrm{~s}$, and $\mathrm{d}_{\mathrm{c}}=8 \mathrm{~cm}$. The latter three quantities scale with minimum patch size. If patches as small as $\mathrm{L}_{\mathrm{c}}=100 \mathrm{~m}$ are permitted to nucleate significant quakes, then $\mathrm{dt}=0.03 \mathrm{~s}, \mathrm{~T}_{\mathrm{c}}=0.24 \mathrm{~s}$ and $\mathrm{d}_{\mathrm{c}}=1.3 \mathrm{~mm}$. This choice requires considerable computation because of the small dt.

\section{Earthquake Healing Conditions:}

Friction law (12.3) says that when slip velocity on a fault segment falls below $v_{c}$, fault strength increases. Strengthening slows the slipping further and the fault quickly locks-up. Numerical experiments with (12.3) demonstrate that once broken, fault elements tend to remain slipping until the earthquake consumes almost all of the available stress excess on the fault. To the contrary, some seismologists contend that slip at a point locks-up rather soon after first failing, causing ruptures to travel down faults as narrow slip pulses (Heaton, 1990). Accelerating the healing process is one means to satisfy these observations. To accelerate healing, I introduce a slip dependence into the velocity weakening law (12.3) as

$$
\mathrm{Q}_{\mathrm{i}}\left(\mathbf{S}_{\mathrm{s}}, \mathrm{S}_{\mathrm{d}}, \mathbf{u}(\mathrm{t}), \mathbf{v}(\mathrm{t}), \mathbf{T}(\mathrm{t})\right)=\max \left[\left(\mathrm{S}_{\mathrm{d}}\right)_{\mathrm{i}},\left(\mathrm{S}_{\mathrm{s}}\right)_{\mathrm{i}}-\Delta \mathrm{S}_{\mathrm{i}} \mathrm{v}_{\mathrm{i}}(\mathrm{t}) /\left[\mathrm{v}_{\mathrm{c}}+\psi \mathrm{u}_{\mathrm{i}}{ }^{\mathrm{n}}(\mathrm{t})\right]\right]
$$

where $u^{n}(t)=u(t)-u\left(t_{n}\right)$ labels slip since nucleation time $t_{n} \cdot t_{n}$ marks the last occasion when $v(t)=0$. At nucleation $\mathrm{u}^{\mathrm{n}}(\mathrm{t})=0$, so modification (21) does not alter conditions (18) to (20).

Parameter $\psi$ in (21) has physical meaning. Suppose that slip near the nucleation position has been in progress for duration $t_{R}=t-t_{n}>d t$. The product of slip speed and slip duration estimates total slip $u^{n}(t)$ at that point

$$
\mathrm{u}^{\mathrm{n}}(\mathrm{t}) \approx \mathrm{v}(\mathrm{t}) \mathrm{t}_{\mathrm{R}}
$$

Suppose also that the rupture extends its length bi-laterally at a speed $\mathrm{v}_{\mathrm{r}}$ from nucleation. The fault dimension at $\mathrm{t}$ is roughly 


$$
\mathrm{L}_{\mathrm{H}} \approx 2 \mathrm{v}_{\mathrm{r}} \mathrm{t}_{\mathrm{R}} \gg 2 \mathrm{v}_{\mathrm{r}} \mathrm{dt}=2 \mathrm{v}_{\mathrm{r}}\left(2 \mathrm{~L}_{\mathrm{c}} / \mathrm{v}_{\mathrm{p}}\right)
$$

From (21), the fault begins to heal when $v(t) /\left[v_{c}+\psi u^{n}(t)\right]$ falls below unity. When healing starts

$$
\psi=\left[\mathrm{v}(\mathrm{t})-\mathrm{v}_{\mathrm{c}}\right] / \mathrm{u}^{\mathrm{n}}(\mathrm{t}) \approx\left[\mathrm{v}(\mathrm{t})-\mathrm{v}_{\mathrm{c}}\right] / \mathrm{v}(\mathrm{t})\left(\mathrm{L}_{\mathrm{H}} / 2 \mathrm{v}_{\mathrm{r}}\right)=\left[2 \mathrm{v}_{\mathrm{r}} / \mathrm{L}_{\mathrm{H}}\right]\left[1-\mathrm{v}_{\mathrm{c}} / \mathrm{v}(\mathrm{t})\right] \approx 2 \mathrm{v}_{\mathrm{r}} / \mathrm{L}_{\mathrm{H}}
$$

because $v(t) \gg>v_{c}$ in a run-away rupture (see Figure 3 ). Equation (24) relates the friction parameter $\psi\left(\approx 2 v_{\mathrm{r}} / \mathrm{L}_{\mathrm{H}}\right)$ to $\mathrm{L}_{\mathrm{H}} \gg \mathrm{L}_{\mathrm{c}}$, a maximum dimension that a rupture will expand to prior to the onset of healing. Rupture velocity $\mathrm{v}_{\mathrm{r}}$ depends on the state of stress on a fault. Rupture velocity changes event to event, and even within an event. Because velocity $v_{p}$ is specified already and because (24) is approximate, it suffices to replace $v_{r}$ by $v_{p}$ in (24) with the result

$$
\mathrm{Q}_{\mathrm{i}}\left(\mathrm{S}_{\mathrm{s}}, \mathrm{S}_{\mathrm{d}}, \mathbf{u}(\mathrm{t}), \mathbf{v}(\mathrm{t}), \mathbf{T}(\mathrm{t})\right) \approx \max \left[\left(\mathrm{S}_{\mathrm{d}}\right)_{\mathrm{i}},\left(\mathrm{S}_{\mathrm{s}}\right)_{\mathrm{i}}-\Delta \mathrm{S}_{\mathrm{i}} \mathrm{v}_{\mathrm{i}}(\mathrm{t}) /\left[\mathrm{v}_{\mathrm{c}}+2 \mathrm{u}_{\mathrm{i}}{ }^{\mathrm{n}}(\mathrm{t}) \mathrm{v}_{\mathrm{p}} / \mathrm{L}_{\mathrm{H}}\right]\right](25)
$$

Using (23) and (24) with $\mathrm{v}_{\mathrm{r}}=\mathrm{v}_{\mathrm{p}}$, the second term in (25)

$$
\left(\mathrm{S}_{\mathrm{s}}\right)_{\mathrm{i}}-\Delta \mathrm{S}_{\mathrm{i}} \mathrm{v}_{\mathrm{i}}(\mathrm{t}) /\left\{\mathrm{v}_{\mathrm{c}}+2 \mathrm{v}(\mathrm{t}) \mathrm{t}_{\mathrm{R}} \mathrm{v}_{\mathrm{p}} / \mathrm{L}_{\mathrm{H}}\right\}=\left(\mathrm{S}_{\mathrm{s}}\right)_{\mathrm{I}}-\Delta \mathrm{S}_{\mathrm{i}} \mathrm{v}_{\mathrm{i}}(\mathrm{t}) /\left\{\mathrm{v}_{\mathrm{c}}+\mathrm{v}_{\mathrm{i}}(\mathrm{t})\right\}
$$

falls between $\left(\mathrm{S}_{\mathrm{s}}\right)_{\mathrm{i}}$ at $\mathrm{v}_{\mathrm{i}}(\mathrm{t})=0$ and $\left(\mathrm{S}_{\mathrm{d}}\right)_{\mathrm{i}}$ as $\mathrm{v}_{\mathrm{i}}(\mathrm{t}) \Rightarrow \infty$. So, provided that $(23)$ holds (i.e. $\left.\mathrm{L}_{\mathrm{H}}>>\mathrm{L}_{\mathrm{C}}\right)$ it is not necessary usually to carry the $\max [\sim]$ function in $(25)$.

Equation (25) represents a fault friction law expressed in terms of a limiting signal velocity $v_{p}$ (nominally, $v_{p}$ equals the P-wave speed), an effective strength $\Delta \mathrm{S}$, and just two easily interpretable parameters: a maximum rupture size prior to healing $\left(\mathrm{L}_{\mathrm{H}}\right)$ and a critical slip velocity $\mathrm{v}_{\mathrm{c}}$, or equivalently, a minimum patch size for rupture nucleation $\mathrm{L}_{\mathrm{c}}$. Figure 3 illustrates typical source time functions generated by inserting (25) into (17). Each panel in the Figure shows the displacement $u^{n}(t)$ and slip velocity $v(t)$ resulting from a stress excess of $\varepsilon=0.02$ bars applied over a patch of dimension L. Larger overstressed patches shorten time-to-failure and increase total slip. Naturally, if the over-stressed patch is smaller than the specified critical size $\mathrm{L}_{\mathrm{c}}$ (bottom panel), only minor slip occurs.

Let me end this section by reminding the reader that the above friction law was designed to produce reasonable rupture behaviors under the limited scope of this model (elastic whole space, two-dimensionality, quasi-static, etc.). Improved Standard Physical Models would likely replace this "friction module" with others that are appropriate for different assumptions.

\section{Steps in Implementation}

Section 2 cast the foundation for the synthetic seismicity models. There remains a few practical aspects of im- 
plementation. Below, I give my approach and some insights gained on the course.

\section{Regarding $\mathbf{R}$}

Ward (1996) provides the formulas for the static response matrix $\mathbf{R}$ under the assumption of two-dimensional plane stress. This "thin plate" formulation limits the system faults to a vertical orientation and a horizontal slip, either tangential or normal. Dipping faults, or faults with a dip-slip component must be handled indirectly. Most of the faults of the San Francisco Bay Area are vertical strike-slip, so two-dimensionally is not a strong restriction for the purposes of this paper. If dip-slip or dipping faults are deemed vital however, the elements of $\mathbf{R}$ might be formed by 3-D stress fields such as the half-space formulas given by Okada (1992). Ultimately, Standard Physical Models should be computed in layered elastic, viscoelastic, or even laterally heterogeneous Earth structures.

\section{Regarding $\boldsymbol{x}_{i}, \mathrm{~b}_{\mathrm{i}}$, and $\mathrm{w}_{\mathrm{i}}$}

Specifying the center $\mathbf{x}_{\mathrm{i}}$ of $\mathrm{N}$ fault elements presents no particular difficulty. For simplicity, I assume a constant value for the half-length and half-width of each fault element. Thus, the dimensions $2 b, 2 \mathrm{w}$, and the total length $\mathrm{L}_{\mathrm{T}}$ of all of the faults in the system fixes the total number of fault elements. Computational resources usually dictate the size of $\mathrm{N}$, in particular, the ability to find $\mathbf{R}^{-1}$ for a matrix of dimension $(\mathrm{N} \times \mathrm{N})$. Faced with boundless computer resources, patch size might be set equal to the physical dimension of the smallest earthquake of interest.

In two-dimensional formulations, the absence of a depth co-ordinate excludes the down dip width $2 \mathrm{w}$, from direct involvement in the calculation. However, because it is useful to translate total earthquake slip into moment and magnitude, I fix $2 \mathrm{w}=11 \mathrm{~km}$, although it could be made variable along strike if needed. The models of Section 4 limit $\mathrm{N}$ to 600 . With $\mathrm{L}_{\mathrm{T}}=1500 \mathrm{~km}$ for the San Francisco Bay Area faults (Figure 1), $2 \mathrm{~b}$ came to $2.6 \mathrm{~km}$.

\section{Regarding $\mathbf{T}_{\mathrm{o}}$}

Unless one wishes to trigger an earthquake with a particular slip distribution at the outset (as I do in Figure 4), the initial stress field is not critical. To reach quickly a representative state of earthquake production, a useful procedure starts the simulation with a saved final stress state from an earlier run. 


\section{Regarding $\mathbf{T}_{\mathrm{p}}$}

The plate tectonic driving stress comes straight from (2), $\mathbf{T}_{\mathrm{p}}=-\mathbf{R} \mathbf{v}_{\text {plate }}$. For faults that physically end, I taper slip rate $\mathbf{v}_{\text {plate }}$ to zero. Similarly, for faults that have a rapid change in slip along strike, I smooth the transition. Smoothing helps soften wide swings in $\mathbf{T}_{\mathrm{p}}$ that would otherwise develop.

\section{Regarding $\mathbf{S}_{\mathrm{s}}$ and $\mathbf{S}_{\mathrm{d}}$}

Slip in earthquakes is fueled by the difference between a fault's static $\mathbf{S}_{\mathrm{s}}$ and dynamic strength $\mathbf{S}_{\mathrm{d}}$. Thus only effective strength $\Delta \mathbf{S}=\mathbf{S}_{\mathrm{s}}-\mathbf{S}_{\mathrm{d}}$ has relevance to the calculation. Effective strength ties directly to geological observations. In 2-D plane stress, characteristic mean slip from a complete stress drop earthquake on a fault segment of length $\mathrm{L}_{\text {seg }}$ is

$$
\mathrm{u}_{\mathrm{seg}}^{\text {char }}=\Delta \mathrm{S}_{\mathrm{seg}} \mathrm{L}_{\mathrm{seg}} \pi / 4 \mu(1+\mathrm{v}) \text {. (26) }
$$

Geologists often have good knowledge of the characteristic slip for fault segments, so $\Delta \mathrm{S}_{\text {seg }}$ is often well constrained. Sometimes, as in the case of the 1906 San Francisco Earthquake (Figure 4), one or more samples of coseismic surface slip exist for faults of the system. This information augments (26) to establish $\Delta \mathbf{S}$. Again be advised that the form and constants in (26) may differ with the conditions (plane strain versus plane stress, 2-D versus 3-D, halfspace versus layered earth) built into the response matrix. Fault strengths $\Delta \mathrm{S}_{\text {seg }}$ needed to produce a specified characteristic slip $\mathrm{u}_{\text {seg }}^{\text {char }}$ on a segment of length $\mathrm{L}_{\mathrm{seg}}$ will therefore be somewhat model dependent.

\section{Regarding $\mathrm{v}_{\mathrm{p}}$}

Certainly the limiting signal speed fed into (10) and (15) can not exceed the crustal P-wave velocity. In the models of Section $4, v_{p}=6 \mathrm{~km} / \mathrm{s}$.

\section{Regarding $\mathrm{L}_{\mathrm{c}}$, $\mathrm{dt}$, and $\mathrm{L}_{\mathrm{H}}$}

Of all the initial settings, the modeller has the most freedom in selecting frictional parameters $\mathrm{L}_{\mathrm{c}}$ and $\mathrm{L}_{\mathrm{H}}$. $\mathrm{L}_{\mathrm{c}}$ can not be smaller than the elemental fault size $2 b$, and from $(23), \mathrm{L}_{\mathrm{H}}$ has to be much greater than $\mathrm{L}_{\mathrm{c}}$. The intra-seismic time step relation $d t=2 L_{c} / v_{p}$ provides guidance in picking $L_{c}$ if a specific temporal resolution dt is desired. The relation might also provide restrictions on $\mathrm{L}_{\mathrm{c}}$ due to the added computational costs that come with smaller interval dt. 
By and large, I select $\mathrm{L}_{\mathrm{c}}$ and $\mathrm{L}_{\mathrm{H}}$ by comparing the behavior of synthetic earthquakes to the behaviors of real earthquakes. After all, my purpose in running these simulations is to reproduce, to the extent that they are known, observed earthquake behaviors. To find use in hazard applications, this is the minimum model requirement. Retaining the freedom to adjust two friction parameters to satisfy this requirement is correct and sensible to me; however, other workers may wish to constrain friction laws and their parameters on the basis of laboratory results and accept whatever earthquake behaviors that arise. The calculations of Section 4 set $\mathrm{L}_{\mathrm{c}}=6 \mathrm{~km}$ and $\mathrm{L}_{\mathrm{H}}=200 \mathrm{~km}$.

\section{San Francisco Bay Area Model}

\section{Bay Area Fault System}

Figure 1 maps the member faults in the San Francisco Bay Area earthquake simulations. The membership includes all faults with slip rates greater than $3 \mathrm{~mm} / \mathrm{y}$ plus a few others with lesser rates. Slip rates and codes H6, A2, etc., come from the 1996 report of the Working Group on Northern California Earthquake Potential (WGNCEP/96). WGNCEP/96 also compiled characteristic slip-per-event information. Small numbers in Figure 1 mark distance along the $1550 \mathrm{~km}$-long fault system.

\section{San Francisco Earthquake.}

As mentioned above, relation (26) most often determines effective strength $\Delta \mathrm{S}_{\text {seg }}$ through characteristic segment slip. Physical models of earthquakes however, have the powerful ability to incorporate a wide range of information. One source of better information are samples of coseismic surface slip. Previous studies have demonstrated (Ward, 1997) that when properly modeled, even a single observation of surface slip can go a long way toward constraining a fault's effective strength distribution. In this field region, the 1906 San Francisco earthquake serves as a guide. Lawson (1908) originally documented surface offsets for the 1906 earthquake. Thatcher et al. (1997) further filled gaps in the surface slip observations by analyzing geodetic data.

Figure 4 details a simulation of the 1906 San Francisco earthquake over a $550 \mathrm{~km}$ long stretch of the San Andreas Fault from the Mendocino Fracture Zone to San Juan Bautista. (Similar detail exists for every earthquake in the 3000 year run.) The dark gray color represents the current effective strength of the fault, i.e. $\mathbf{Q}(\mathrm{t})-\mathbf{S}_{\mathrm{d}}$. Current 
effective strength equals $\Delta \mathbf{S}$, a fixed physical characteristic except at points where the fault is slipping. The light gray color represents the current effective stress on the fault, i.e. $\mathbf{T}(\mathrm{t})-\mathbf{S}_{\mathrm{d}}$. Current effective stress is not a fixed physical characteristic, it changes between, and within ruptures. In this case, I selected the initial distribution of effective stress (light gray, top line) and effective strength $\Delta \mathbf{S}$ so that the model quake reproduced the surface slip of the 1906 San Francisco earthquake (squares, bottom). A good fit to the surface slip was possible with a single variation in effective strength, from 20 to 30 bars in northern Mendocino (km \#90). Note that the Fort Ross slip

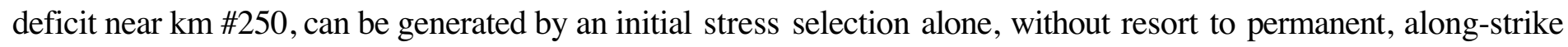
changes in effective strength. Matching the deficit however, did require that that section of the fault be empty of initial effective stress. The 3000 year simulations rarely report large sections of faults being completely empty or full of stress. For this reason, 20 to 30 bars represents minimum values for $\Delta \mathbf{S}$ near Fort Ross, or indeed, for most of the fault north of the Golden Gate (GG).

As did the actual 1906 earthquake (Bolt, 1968; Wald, et al., 1993), the model earthquake nucleates near the Golden Gate and propagates bi-laterally toward the north and south. Note that the rupture speeds up where the stress barrier $\left[\mathrm{S}_{\mathrm{s}}-\mathrm{T}(\mathrm{t})\right]$ forward of the rupture is low, and slows down where the forward stress barrier is high. The "finger print" at the bottom of Figure 4 plots the evolution of slip at 2-second intervals. You can see that the rupture takes over a dozen seconds to breach the stress barrier at Fort Ross. Rupture actually jumped across the barrier near km\#220 before the middle of the barrier finally collapsed. Admittedly, no one knows the slip history of the 1906 earthquake to this level of detail. Still, Figure 4 testifies that realistic rupture simulations are achievable within a modified quasi-static framework and that such simulations furnish physically defensible implications of other information (such as the Fort Ross slip deficit) on rupture evolution.

Through equation (11), earthquake ground motions link directly to the rupture simulations. Figures 5 and 6 demonstrate this link with the displacements, velocities and accelerations excited by the 1906 earthquake model. Figure 5 plots ground motion up to $10 \mathrm{~Hz}$ at the south pier of the Golden Gate Bridge $\left(37.813^{\mathrm{O}} \mathrm{N}, 122.477^{\circ} \mathrm{W}\right)$ and at Oakland City Center $\left(37.804^{\circ} \mathrm{N}, 122.269^{\circ} \mathrm{W}\right)$. Figure 6 traces ground motions at Point Arena $\left(38.958^{\circ} \mathrm{N}\right.$, $\left.123.738^{\circ} \mathrm{W}\right)$ and at San Juan Bautista $\left(36.844^{\circ} \mathrm{N}, 121.535^{\circ} \mathrm{W}\right)$. The character of ground shaking at South Pier and Oakland differs distinctly from that at Pt. Arena and San Juan Bautista where large, long period (5-10s) velocity 
pulses dominate. The latter two sites lie far north and south along the strike of the San Andreas fault, so directivity of the bi-lateral 1906 rupture heavily influenced waveforms there. This calculation approximated uniform slip fault elements with point sources distributed at 850 meter intervals and it employed modified whole-space Green's functions. The modification multiplies P-wave Green's function terms by $2\left(\rho_{1} \alpha_{1} / \rho_{0} \alpha_{0}\right)^{1 / 2}$ and S-wave terms by $2\left(\rho_{1} \beta_{1} / \rho_{0} \beta_{0}\right)^{1 / 2}$. The " 2 " accounts roughly for the Earth's free-surface. The ratio accounts for the amplification induced by waves transiting to surface layers that are weak relative to the material at the fault. I use values $\left(\rho_{0}=2.5 \mathrm{gm} / \mathrm{cm}^{3}, \alpha_{0}=6.0 \mathrm{~km} / \mathrm{s}, \beta_{0}=3.46 \mathrm{~km} / \mathrm{s}\right.$ and $\left.\rho_{1}=2.35 \mathrm{gm} / \mathrm{cm}^{3}, \alpha_{1}=4.1 \mathrm{~km} / \mathrm{s}, \beta_{1}=1.5 \mathrm{~km} / \mathrm{s}\right)$ typical of crystalline bedrock and Tertiary rock respectively. By substituting more realistic Green's functions computed in 2-D and 3-D earth structures, credible site/source-specific synthetic ground motions can be computed at any position, for any earthquake in this simulation. With multiple calculations of ground motions from a long suite of rupture scenarios, the statistics of shaking exceedence can be deduced directly without reference to empirical attenuation relations.

Figure 7 pictures the time-dependent induced stress changes due to the developing 1906 rupture on all of the other members of the Bay Area fault system. The Figure lays the faults end to end and separates them by vertical lines. During any earthquake, Coulomb stresses at a point can rise then fall, or vice-versa. Intra-rupture stresses may not resemble the final static condition. In this example, the piecewise constant initial stresses were such that the 1906 event triggered a M7.2 earthquake on the North Maacama fault (A6). Responsibility for the 50 second time delay in the triggering of the "co-shock" lies partly with the finite speed of signal propagation $\mathrm{v}_{\mathrm{p}}$, and partly with the time needed for the mainshock to slip enough to build significant stress perturbations on the distant fault. Closer faults; the northern San Gregorio (A5), the southern Calaveras (C1) and the Sargent (A7), host much stronger stress changes. It is easy to imagine that stress induced triggering and segment-jumping ruptures will be common in the 3000 year catalog.

\section{0 year simulation}

Roughly ten samples of every type of fault rupture are needed to quantify earthquake recurrence statistics adequately. Certain earthquakes in the San Francisco Bay Area may have repeat times of several hundred years, so the task of earthquake probability estimation calls for catalogs spanning several thousand years. In the absence of a real catalog of this duration, the call goes out to physical earthquake models. Figure 8 replays a 3000 year se- 
quence of earthquakes on the major faults of the San Francisco Bay Area starting with the system state remaining at the end of the 1906 rupture (bottom Figure 7). The "movie" frames do not space regularly in time, rather they update on the occurrence of an $M>7$ event listed to the upper right in each frame. Line segments of red coloring mark $\mathrm{M}>7.5$ earthquakes; orange coloring, $7<\mathrm{M}<7.5$; and the thick and thin black coloring, $6.5<\mathrm{M}<7$ and $6<\mathrm{M}<6.5$ respectively. Note the richness of scenarios and irregular clustering excited by stress interactions. Intervals between M7 events can be as little as 4 years or more than 150 years. It is not hard to visualize certain premonitions or cause and effects; say, the M7 San Andreas event in 334.5 announcing the impending arrival of a M7.7 in 338 , or the M7.7 rupture in 730 "finishing its business" in 740.5 (M7.0) by breaking the Santa Cruz Mountains segment of the fault that it had missed earlier. Other patterns, such as large San Andreas quakes shutting off subsequent activity on the East Bay faults, are more subtle, but they make perfect fodder for pattern recognition schemes (e.g., Rundle et al., 1998).

Figure 9 illustrates the coseismic slip history for the 3000 year run of synthetic seismicity. Each pillow outlines the slip in one of the events in Figure 8. Note that in the long term, as a consequence of (2), earthquake history on each fault exactly reproduces its specified geological slip rate. The gray line along the top of the figure marks the effective strength of the faults as deduced from (26). The black line along the top maps the annual rate of tectonic loading, $\mathbf{T}_{\mathrm{p}} \times 100 . \mathbf{T}_{\mathrm{p}}$ can be wiggly for faults with variable slip rate along strike and for those with steps and bends. Witness the large peak in loading rate near the Golden Gate (GG) due to the presence there of a $3 \mathrm{~km}$ rightstep in the San Andreas Fault. Because of their role in concentrating the interseismic loading function, fault steps and jogs act as permanent nucleation centers for earthquakes.

Figure 10 gives an alternative representation of the seismicity of Figure 8 with horizontal lines marking the position and date of M6+ earthquakes. See now, the large number of M6 events crowding the Golden Gate Step. Fault steps not only serve as foci for rupture nucleation, they also influence rupture termination. The number of M7+ ruptures that terminated near the Golden Gate Step clearly exceeds the number that would be expected by chance. Physical earthquake models provide the best means to evaluate the impact of mapped fault geometries on the patterns of earthquake recurrence. 
This simulation ignites earthquakes over a wide magnitude range. Figure 11 plots the annual rate of earthquakes greater than magnitude M produced by the model (circles) versus those in the Ellsworth (1990) catalog (squares). The simulation does a good job in reproducing the rates of observed earthquakes down to $M=6$, the point at which the Ellsworth catalog lacks completeness. The agreement between catalog and computed earthquake rates is another indication that the seismicity model is functioning properly within the bounds of observed earthquake behavior.

Figure 12 magnifies the final slip distribution of all M>6.5 quakes on the San Andreas Fault. In close-up, the character of individual ruptures is far more expressive than the line plots of Figure 8 or Figure 10 might suggest. Physical earthquake models provide a means to interpret these expressions. For example, previous experiments (Ward, 1997) have shown that locations where the slip function is concave up tend be left at a higher state of effective stress after the earthquake than they were prior to it. Concave-up locations attract subsequent "fill-in" earthquakes as exemplified by the event pairs in years 338 and 432, and 912 and 941 . Being geometrically correct, rupture encyclopedias computed from physical earthquake models can be compared directly with site-specific paleoseismic studies (e.g. Grizzly Flat, km \#480, Schwartz et al., 1998) that quantify slip-per-event and variation in slipper-event.

\section{Conclusions}

This paper demonstrates the feasibility of constructing a Standard Physical Earthquake Model for the San Francisco Bay Area. Physical models represent the best existing means to quantify earthquake recurrence in a region characterized by closely spaced, sub-parallel faults. Physical models serve as a platform for: 1) data utilization and verification, any earthquake statistic that is measurable in the field or in the laboratory can be compared directly with, and used to tune and test seismicity model products; 2) probability forecasts, a physical earthquake model supplies rational estimates of every imaginable earthquake statistic while simultaneously satisfying all slip and earthquake rate constraints; and 3) hazard analysis, a physical earthquake model catalogs suites of detailed rupture scenarios for every fault in the system. Convolving these slip histories with site-specific dislocation Green's functions produces a full set of shaking time-series at any desired position. Probabilistic estimates of shaking intensity can be constructed directly from this set of synthetic seismograms without need for empirical attenuation relations. 
Physical earthquake models have advanced greatly in the last decade. Simulations of earthquake generation and recurrence are now sufficiently realistic that such calculations can begin to take substantial roles in scientific studies that estimate earthquake probabilities and hazard. On the horizon lay vastly improved earthquake simulations that will lift the restrictive assumptions of this vanguard and carry the promise to full potential.

Acknowledgments: I thank Steven Day, Mitsuhiro Matsu'ura, and an anonymous reviewer for helpful comments. This research was supported by Southern California Earthquake Center Award 662703, USGS Contract \# 14343-HQ-98-GR-00047 and NSF Contract EAR-9804970. Southern California Earthquake Center contribution 487. Contribution 409 of the Institute of Tectonics, University of California, Santa Cruz, CA 95064. [ward@uplift.ucsc.edu]

\section{References}

Bolt, B. A., 1968, The focus of the 1906 California earthquake, Bull. Seism. Soc. Am., 58, 457-471.

Dieterich, J. H., 1992, Earthquake nucleation of faults with rate and state dependent friction, Tectonophysics, 211, 115-134.

Dieterich, J. H., 1994, A constitutive law for rate of earthquake production and its application to earthquake clustering, J. Geophys. Res. 99, 2601-2618.

Dieterich, J. H. and D. Kilgore, 1996, Implications of fault constitutive properties for earthquake prediction, Proc. Natl. Acad. Sci., 93, 3787-3794.

Ellsworth, W. L., 1990, "Earthquake History", in The San Andreas Fault System, California, U.S.G.S prof. paper 1515.

Harris, R. A. and R. W. Simpson, 1998, Suppression of large earthquakes by stress shadows: A comparison of Coulomb and rateand-state failure, J. Geophys. Res., 103, 24,439-24,451.

Heaton, T. H., 1990, Evidence for and implications of self-healing pulses of slip in earthquake rupture, Physics of the Earth and Planetary Interiors, 64, 1-20. 
Jaume, S. C., and L. R. Sykes, 1996, Evolution of moderate seismicity in the San Francisco Bay Region, 1850 to 1993: Seismicity changes related to the occurrence of large and great earthquakes, J. Geophys. Res., 101, 765-789.

Lawson, A. C., 1908, The California Earthquake of April 18, 1906, Report of the State Earthquake Investigation Commission, Carnegie Inst. of Washington, Washington D. C.

Okada, Y., 1992. Internal deformation due to shear and tensile faults in a half-space, Bull. Seism. Soc. Am., 82, 1018-1040.

Rundle, J. B., W. Klein, and K. Tiampo, 1998, Linear Pattern dynamics in nonlinear threshold systems, Phys. Rev. Lett., submitted.

Schwartz, D. P., D. Pantosti, K. Okumura, T. J. Powers, and J. C. Hamilton, 1998, Paleoseismic investigations in the Santa Cruz mountains, California: Implications for recurrence of large-magnitude earthquakes on the San Andreas Fault, J. Geophys. Res.,103, $17,985-18,001$.

Simpson, R. W. and P. A. Reasenberg, Earthquake-induced static stress changes on central California faults, in The Loma Prieta California Earthquake of October 17, 1989 - Tectonic processes and models, edited by R. W. Simpson, U.S. Geol. Surv. Prof. Pap., 1550-F, F55-F89, 1994.

Thatcher, W., G. Marshall and M. Lisowski, 1997. Resolution of fault slip along the 470-km-long rupture of the great 1906 San Francisco earthquake, J. Geophys. Res, 102, 5353-5367.

Wald, D. J., H. Kanamori, D. V. Helmberger and T. H. Heaton, 1993, Source study of the 1906 San Francisco Earthquake, Bull. Seism. Soc. Am., 83, 981-1019.

Ward, S. N., 1991. Synthetic Seismicity Models for the Middle America Trench, J. Geophys. Res., 96, 19,800-19,810.

Ward, S. N., 1996. A synthetic seismicity model for southern California: Cycles, Probabilities, Hazards, J. Geophys. Res., 101, 
$22,393-22,418$.

Ward, S. N., 1997. Dogtails versus Rainbows: Synthetic earthquake rupture models as an aid in interpreting geological data, Bull. Seism. Soc. Am., 87, 1422-1441.

WGCEP, 1990. Probabilities of large earthquakes in the San Francisco Bay Region, California: USGS Circular, v. 1053.

WGNCEP, 1996. Database of potential sources for earthquakes larger than Magnitude 6 in northern California, USGS Open File report, 96-705.

\section{Figure Captions}

Figure 1. Base map showing the faults included in the San Francisco Bay Area earthquake simulations. Fault codes H6, A2, etc., come from the 1996 report of the Working Group on Northern California Earthquake Potential. Small numbers label distance in km. These can be used to locate corresponding map positions in Figures 4 through 12. This fault system includes a $3 \mathrm{~km}$ right step in the San Andreas Fault at the Golden Gate (km \#375).

Figure 2. Slip velocity versus time calculated from (17) for an $\varepsilon$ stress excess, or initial velocity $(4 \varepsilon / \Delta S) v_{c}$, applied to patches of various sizes. Small initial perturbations parent run-away instabilities only if they are applied over patches of dimension $\mathrm{L}>\mathrm{L}_{\mathrm{c}}$. The squares give time-to-failure on the critical patch for various initial velocities. For example if $v_{\text {initial }}=10^{-4} \mathrm{v}_{\mathrm{c}}$, then $\mathrm{T}_{\mathrm{c}}=11 \times 2 \mathrm{~L}_{\mathrm{c}} / \mathrm{v}_{\mathrm{p}}$.

Figure 3. Typical earthquake time histories generated by placing friction law (25) into formula (17). Friction parameters are $\Delta \mathrm{S}=20$ bars, $\mathrm{L}_{\mathrm{c}}=3 \mathrm{~km}$ and $\mathrm{L}_{\mathrm{H}}=100 \mathrm{~km}$. Using $\mathrm{v}_{\mathrm{p}}=6 \mathrm{~km} / \mathrm{s}$, the critical slip velocity is $\mathrm{v}_{\mathrm{c}}=4 \mathrm{~cm} / \mathrm{s}$. The panels show slip velocity and displacement resulting from a stress excess $\varepsilon=0.02$ bar applied to patches of dimension L. Note that slip velocity in the run-away failures on the patches $\mathrm{L}>\mathrm{L}_{\mathrm{c}}$, far exceeds $\mathrm{v}_{\mathrm{c}}$.

Figure 4. Simulation of the 1906 San Francisco earthquake over a $550 \mathrm{~km}$ long stretch of the San Andreas Fault from the Mendocino Fracture Zone (MFZ, left) to San Juan Bautista (SJB, right). The dark gray color represents the current effective strength of the fault. The light gray color represents the current effective stress on the fault. The initial distribution of effective stress (light gray, top 
line) was selected so that the synthetic quake reproduced the surface slip of the 1906 San Francisco earthquake (squares, bottom) as inferred by the geodetic analysis of Thatcher et al. (1997). Time since nucleation is listed to the left, and the black coloring highlights actively sliding parts of the fault.

Figure 5. Ground motions from the 1906 San Francisco earthquake simulation of Figure 4. Displacements, velocities and accelerations are shown at the South Pier of the Golden Gate Bridge (left) and at Oakland City Center (right). The numbers list the peak value in each trace. South Pier (10 km from the fault) shakes about twice as intensely as Oakland Center ( $25 \mathrm{~km}$ from the fault). This simulation employs modified whole space Green's functions that include all near-field terms. Use of more realistic Green's functions that account rigorously for the free surface and for weaker near-surface structural units could increase shaking intensity considerably.

Figure 6. Ground motions from the 1906 San Francisco earthquake simulation of Figure 4. Displacements, velocities and accelerations are shown at Point Arena (5 km from the fault) and at San Juan Bautista (1 km from the fault). Velocities and accelerations at these sites are roughly twice as large of those at South Pier due to rupture directivity.

Figure 7. Stress effects of the 1906 rupture. To the left appears the developing 1906 rupture. To the right are the time-dependent induced changes in effective stress on all of the other faults of the system. Vertical lines separate individual faults. During rupture, Coulomb stresses can rise then fall, or vice-versa. Intra-rupture stresses may not resemble the final static condition. In this case, a M7.2 earthquake on the North Maacama Fault was triggered some 50 seconds after the nucleation of the main event.

Figure 8. 3000 year sequence of earthquakes on the major faults of the San Francisco Bay Area following the 1906 event. The included faults appear in red in the upper left panel. The "movie" frames are not regularly spaced in time, but they update on the occurrence of an $\mathrm{M}>7$ event listed to the upper right in each frame. Red coloring marks $\mathrm{M}>7.5$ earthquakes; orange coloring, $7<\mathrm{M}<7.5$; and the thick and thin black lines, $6.5<\mathrm{M}<7$ and $6<\mathrm{M}<6.5$ respectively. At the lower left in each panel is time in years since the start of the simulation. The interseismic time step interval is $\Delta \mathrm{T}=0.5 \mathrm{yr}$.

Figure 9. Seismic slip history for the 3000 year run of Bay Area synthetic seismicity. Each pillow represents the slip in one of the events in Figure 8. Magnitudes are listed for M7.5+ events. Gray line along the top traces the effective strength of the faults, $\Delta \mathbf{S}$. Black line along the top is the annual rate of tectonic loading, $\mathbf{T}_{\mathrm{p}} \times 100$. Witness the large peak in loading rate near the Golden Gate 
(GG) due to the right step there.

Figure 10. Space time seismicity plot for the San Francisco Bay Area covering a 3000 year span. Each horizontal line maps the position and time of a M6+ earthquake. Note the large number of M6 events generated near the Golden Gate (GG) due to the presence there of a $3 \mathrm{~km}$ right-step in the San Andreas Fault.

Figure 11. Annual rate of earthquakes greater than magnitude $M$ as produced by the simulation (circles) and the Ellsworth catalog (squares). The simulation reproduces the rates of observed earthquakes down to $M=6$, the point at which the Ellsworth catalog is no longer considered to be complete. The absence of many small unmodelled faults likely accounts for the tail-off in rates near M=5.

Figure 12. Details of the final slip distributions of all $M>6.5$ quakes on the San Andreas Fault for the first 2600 years of the 3000 year simulation. Magnitude and year of occurrence are listed to the left of each trace. Dark gray, light gray and unfilled events are $\mathrm{M}>7.5,7<\mathrm{M}<7.5$ and $6.5<\mathrm{M}<7$ respectively. Rupture encyclopedias like this can be compared directly with site-specific paleoseismic studies that quantify slip-per-event and variation in slip-per-event. 


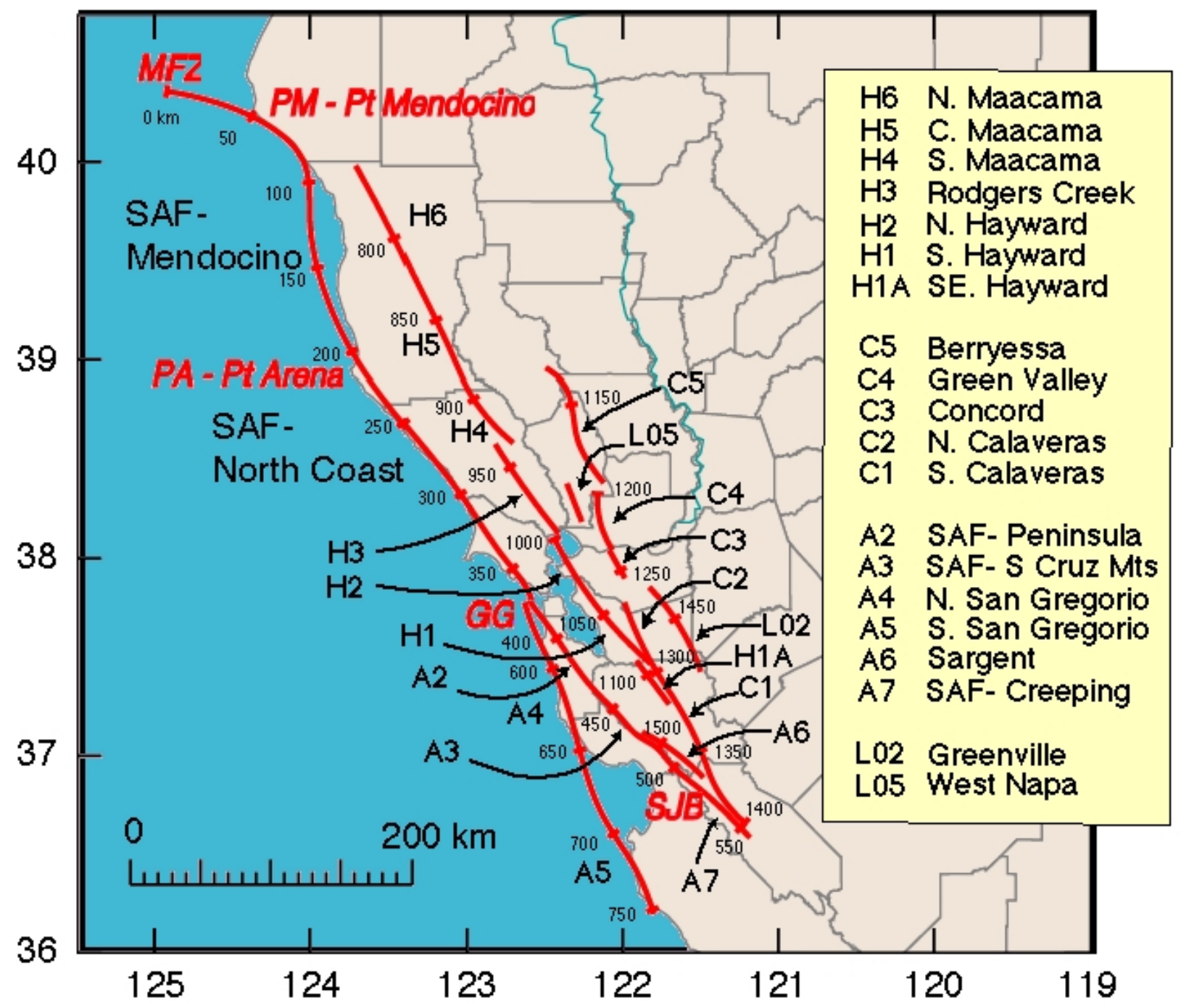

Figure 1. Base map showing the faults included in the San Francisco Bay Area earthquake simulations. Fault codes H6, A2, etc., come from the 1996 report of the Working Group on Northern California Earthquake Potential. Small numbers label distance in $\mathrm{km}$. These can be used to locate corresponding map positions in Figures 4 through 12 . This fault system includes a 3km right step in the San Andreas Fault at the Golden Gate (km \#375). 


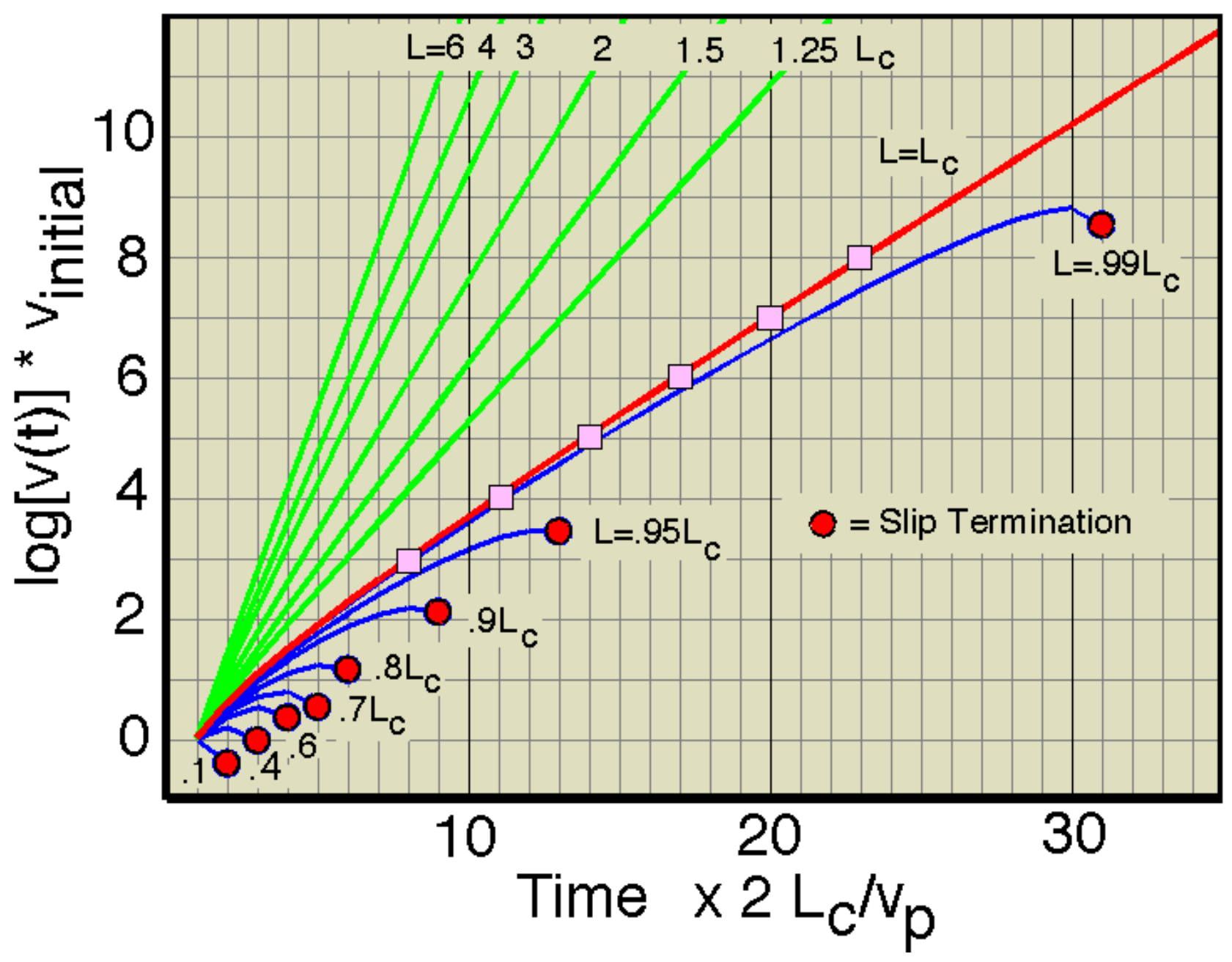

Figure 2. Slip velocity versus time calculated from (17) for an $\varepsilon$ stress excess, or initial velocity $(4 \varepsilon / \Delta S) v_{c}$, applied to patches of various sizes. Small initial perturbations parent run-away instabilities only if they are applied over patches of dimension $\mathrm{L}>\mathrm{L}_{\mathrm{c}}$. The squares give time-to-failure on the critical patch for various initial velocities. For example if $\mathrm{v}_{\text {initial }}$ $=10^{-4} \mathrm{v}_{\mathrm{c}}$, then $\mathrm{T}_{\mathrm{c}}=11 \times 2 \mathrm{~L}_{\mathrm{c}} / \mathrm{v}_{\mathrm{p}}$. 


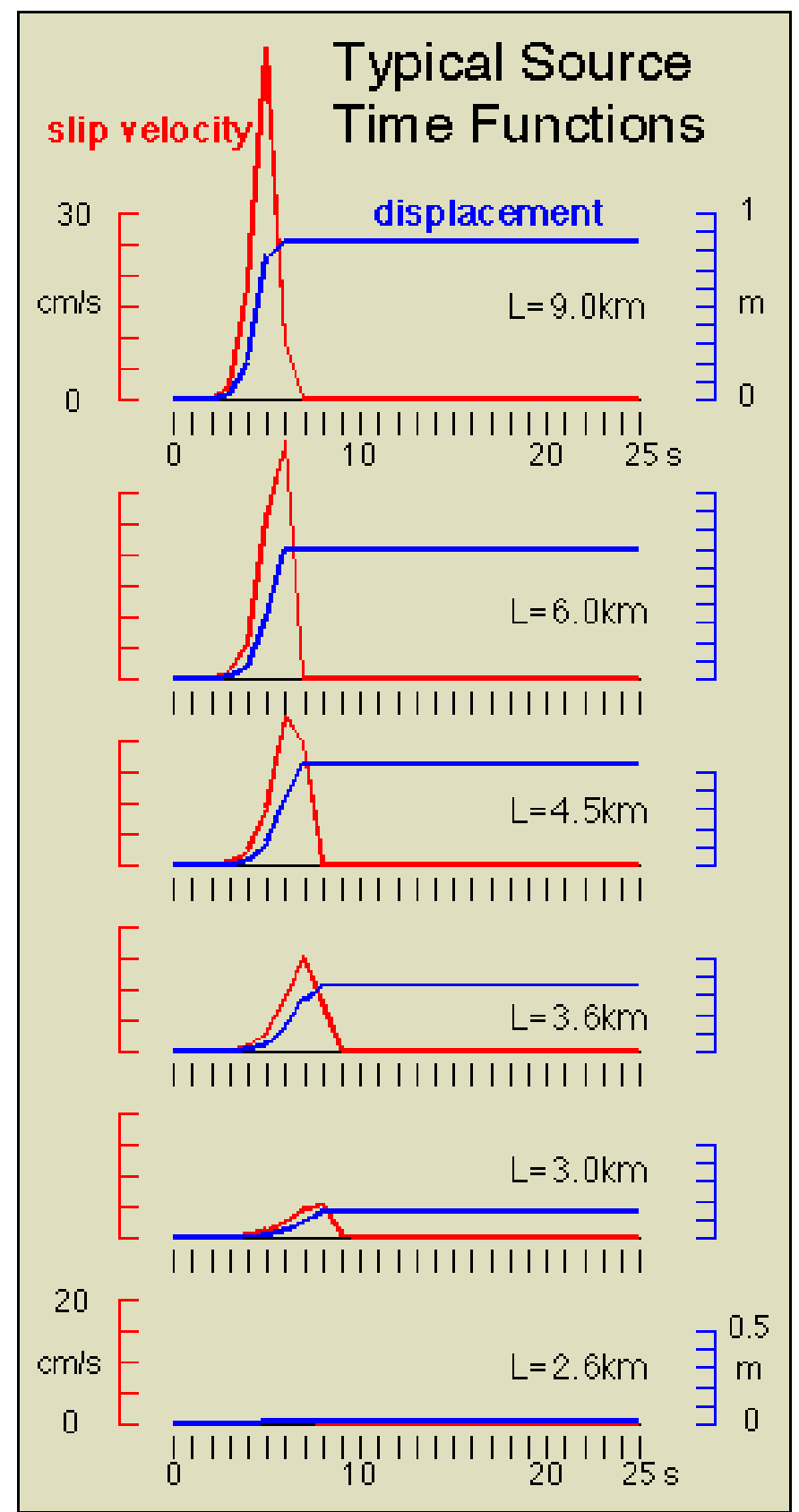

Figure 3. Typical earthquake time histories generated by placing friction law (25) into formula (17). Friction parameters are $\Delta S=20$ bars, $L_{c}=3 \mathrm{~km}$ and $L_{H}=100 \mathrm{~km}$. Using $v_{p}=6 \mathrm{~km} / \mathrm{s}$, the critical slip velocity is $\mathrm{v}_{\mathrm{c}}=4 \mathrm{~cm} / \mathrm{s}$. The panels show slip velocity and displacement resulting from a stress excess $\varepsilon=0.02$ bar applied to patches of dimension L. Note that slip velocity in the run-away failures on the patches $\mathrm{L}>\mathrm{L}_{\mathrm{c}}$, far exceeds $\mathrm{v}_{\mathrm{c}}$. Even as a stand-alone, simple velocity weakening law (25) generates seismically reasonable source time functions. By coupling the law with a geographically correct distribution of faults in the full simulations, realistic products emerge (see Figure 5). 


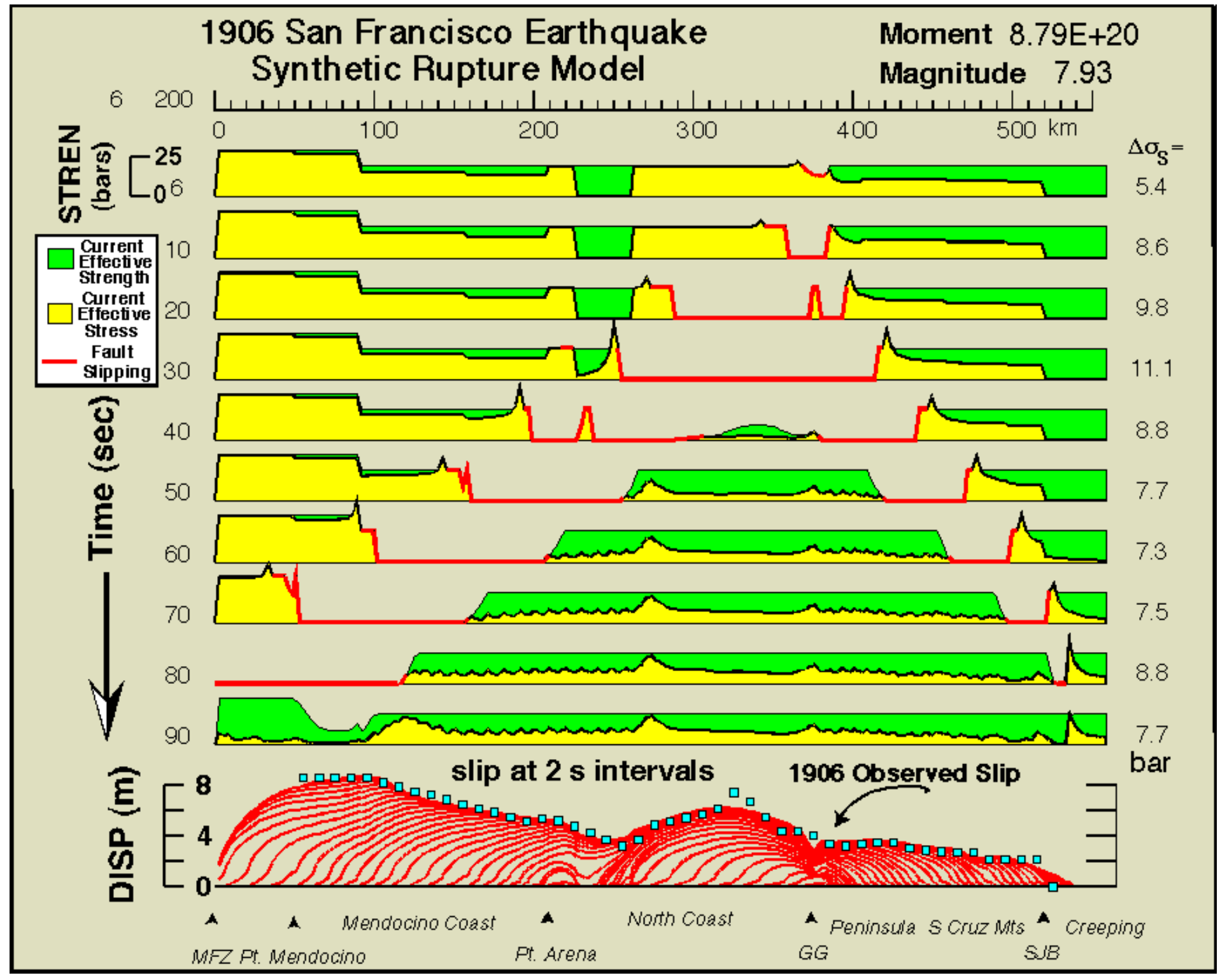

Figure 4. Simulation of the 1906 San Francisco earthquake over a $550 \mathrm{~km}$ long stretch of the San Andreas Fault from the Mendocino Fracture Zone (MFZ, left) to San Juan Bautista (SJB, right). The dark gray color represents the current effective strength of the fault. The light gray color represents the current effective stress on the fault. The initial distribution of effective stress (light gray, top line) was selected so that the synthetic quake reproduced the surface slip of the 1906 San Francisco earthquake (squares, bottom) as inferred by the geodetic analysis of Thatcher et al. (1997). Time since nucleation is listed to the left, and the black coloring highlights actively sliding parts of the fault. 


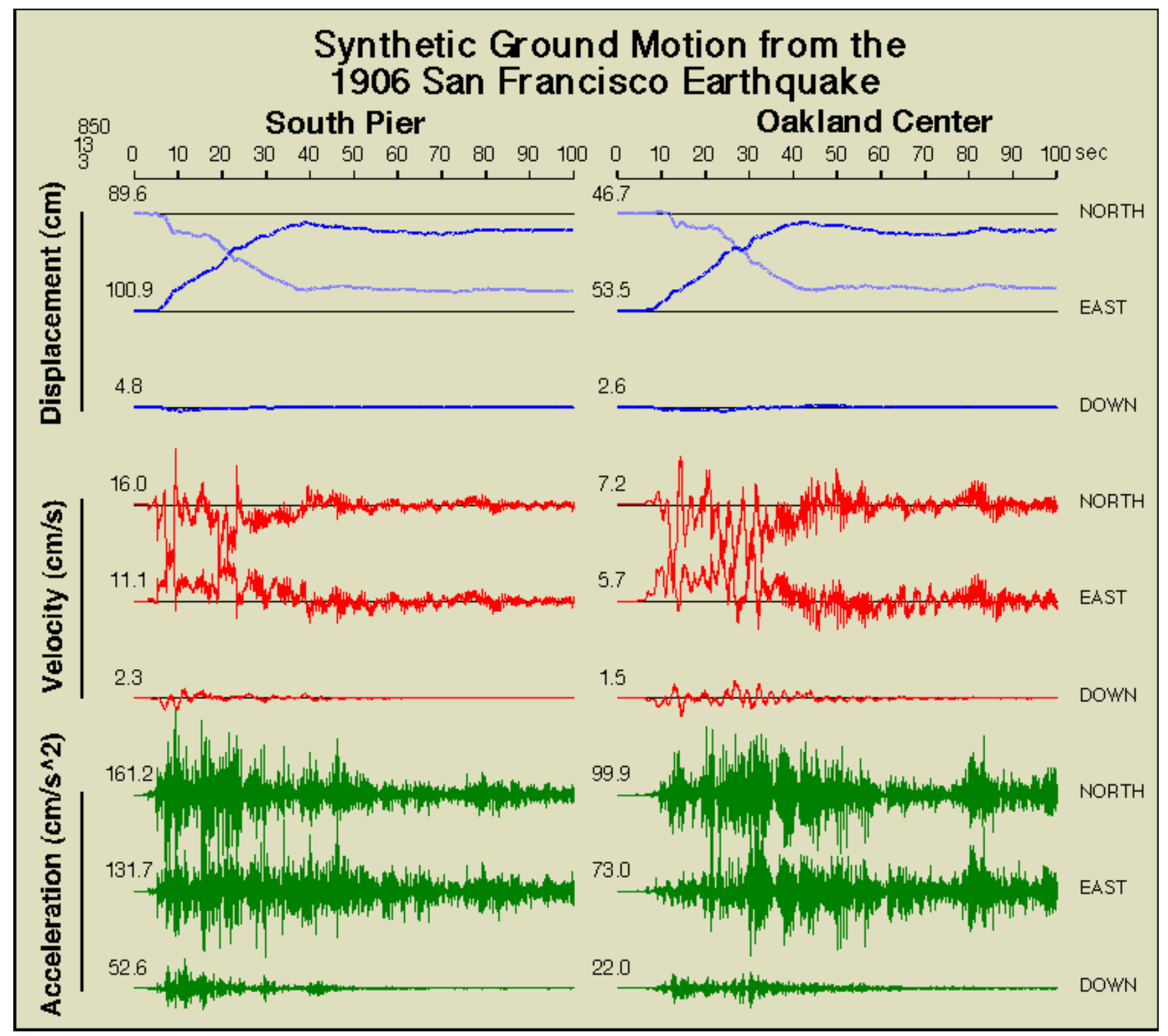

Figure 5. Ground motions from the 1906 San Francisco earthquake simulation of Figure 4. Displacements, velocities and accelerations are shown at the South Pier of the Golden Gate Bridge (left) and at Oakland City Center (right). The numbers list the peak value ir each trace. South Pier (10 km from the fault) shakes about twice as intensely as Oakland Center ( $25 \mathrm{~km}$ from the fault). This simulatior employs modified whole space Green's functions that include all near-field terms. Use of more realistic Green's functions that accoun rigorously for the free surface and for weaker near-surface structural units could increase shaking intensity considerably. 


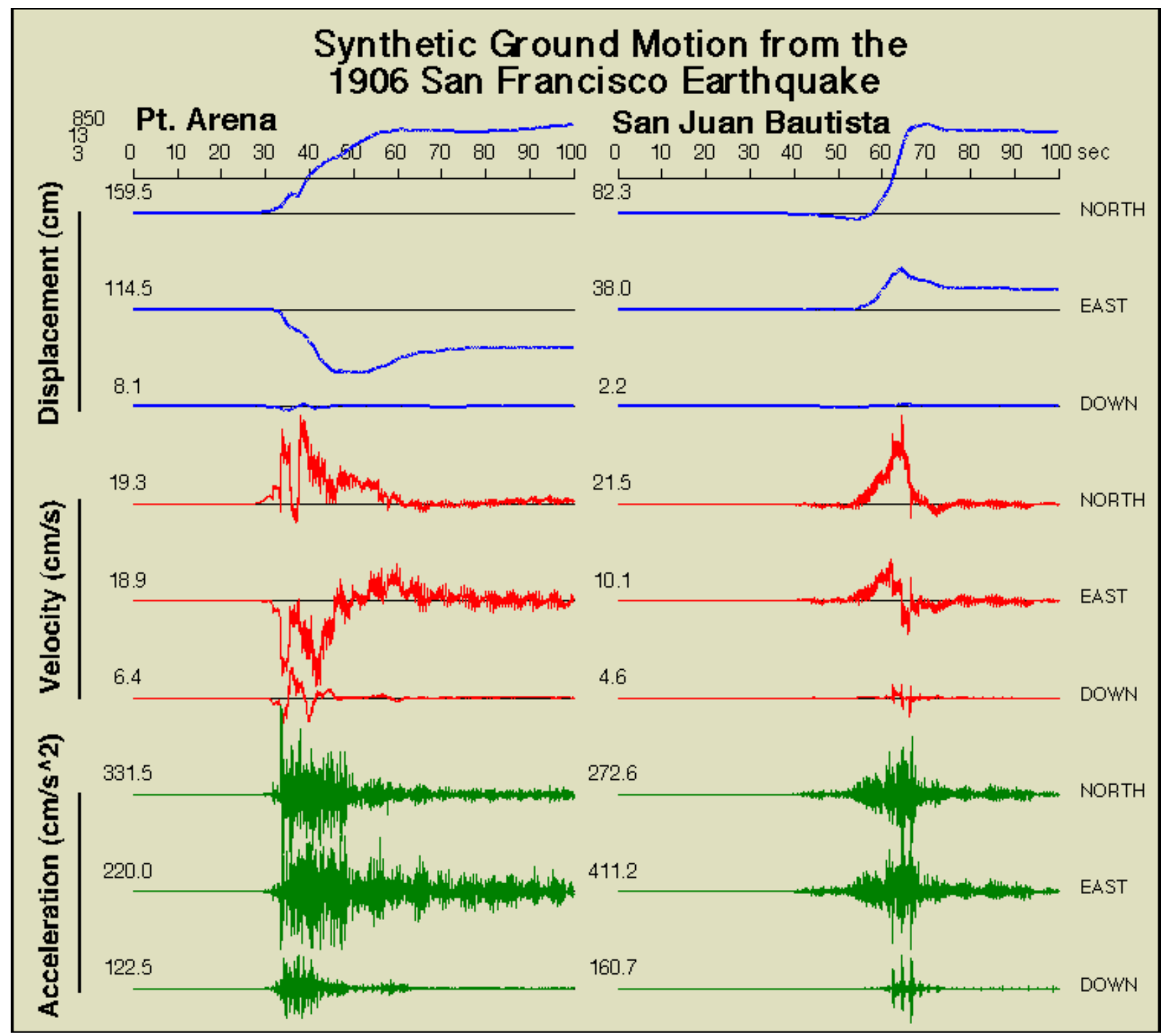

Figure 6. Ground motions from the 1906 San Francisco earthquake simulation of Figure 4. Displacements, velocities and accelerations are shown at Point Arena (5 km from the fault) and at San Juan Bautista (1 km from the fault). Velocities and accelerations at these sites are roughly twice as large of those at South Pier due to rupture directivity. 


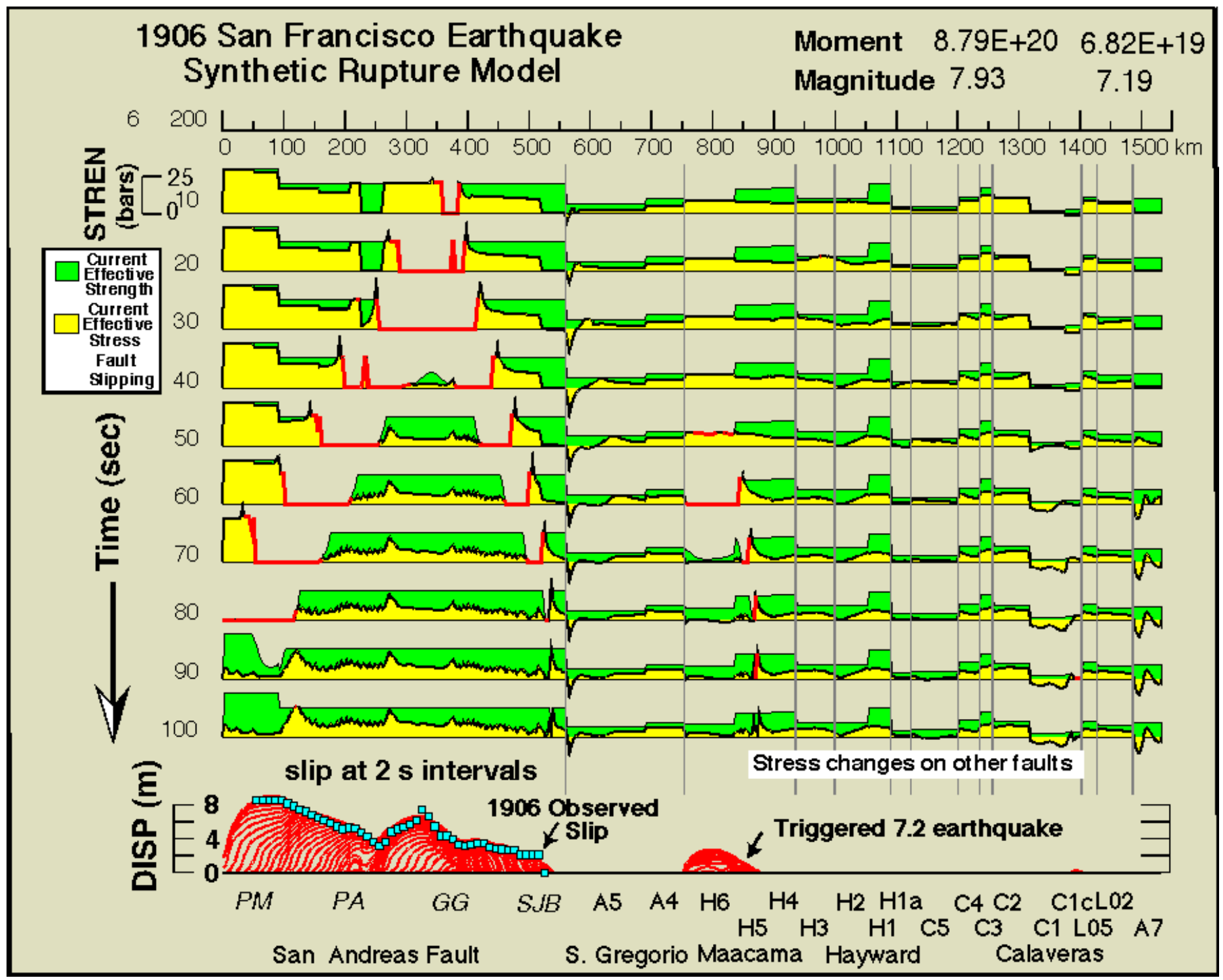

Figure 7. Stress effects of the 1906 rupture. To the left appears the developing 1906 rupture. To the right are the time-dependent induced changes in effective stress on all of the other faults of the system. Vertical lines separate individual faults. During rupture, Coulomb stresses can rise then fall, or vice-versa. Intra-rupture stresses may not resemble the final static condition. In this case, a M7.2 earthquake on the North Maacama Fault was triggered some 50 seconds after nucleation of the main event. 

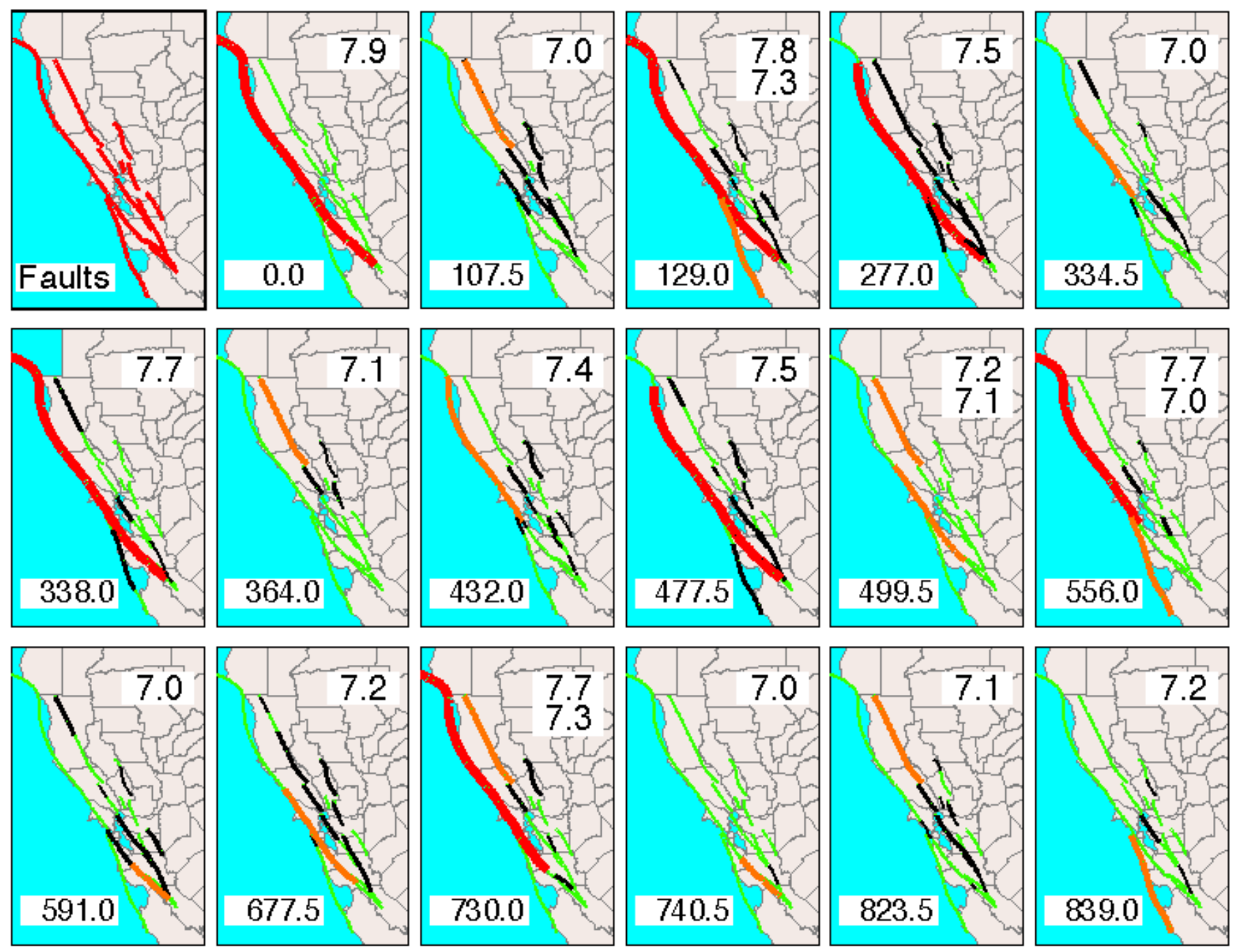

Figure 8. 3000 year sequence of earthquakes on the major faults of the San Francisco Bay Area following the 1906 event. The included faults appear in red in the upper left panel. The "movie" frames are not regularly spaced in time, but they update on the occurrence of an $\mathrm{M}>7$ event listed to the upper right in each frame. Red coloring marks M>7.5 earthquakes; orange coloring, $7<\mathrm{M}<7.5$; and the thick and thin black lines, $6.5<\mathrm{M}<7$ and $6<\mathrm{M}<6.5$ respectively. At the lower left in each panel is time in years since the start of the simulation. The interseismic time step interval is $\Delta \mathrm{T}=0.5 \mathrm{yr}$. 

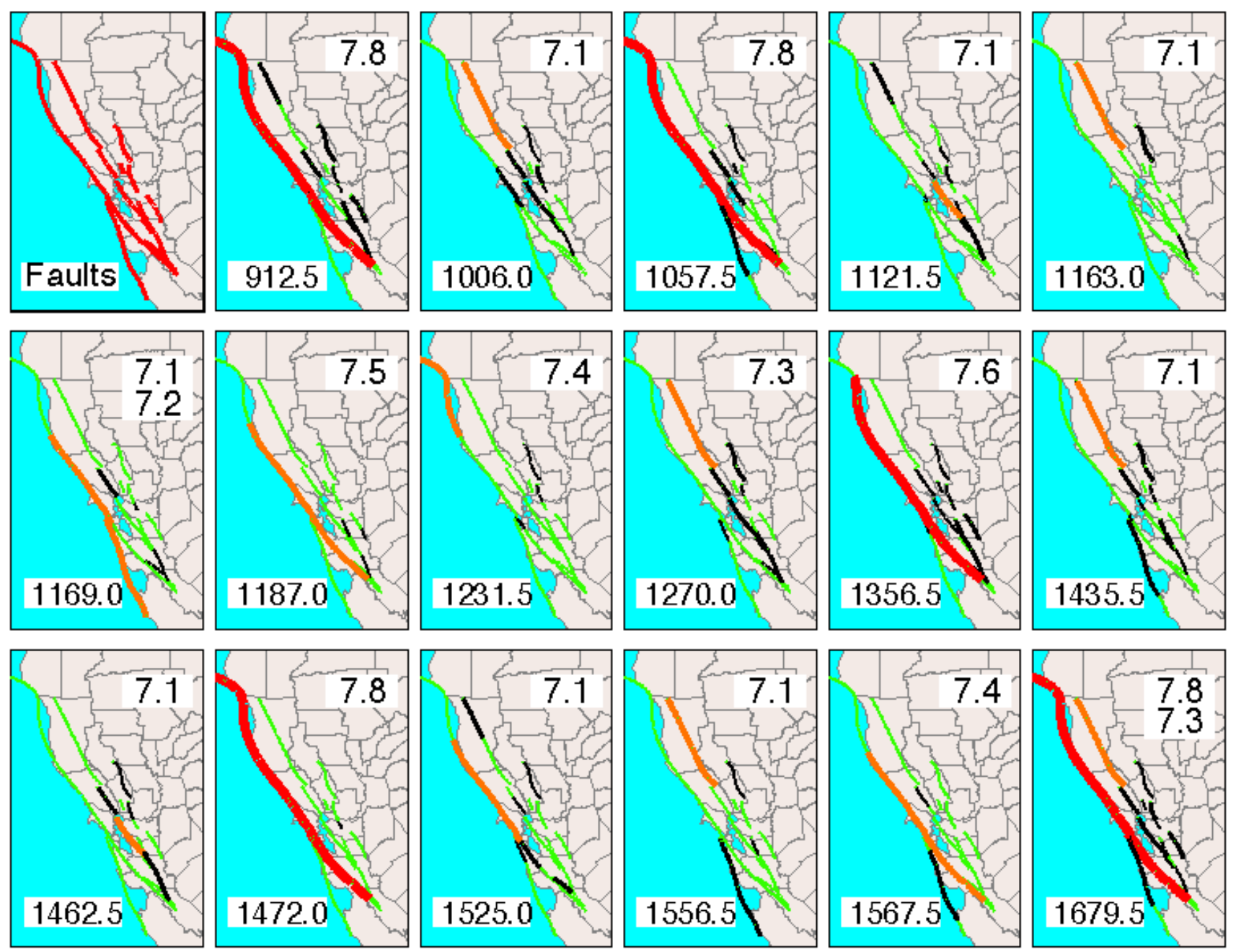

Figure 8.2 "Movie" continued. 

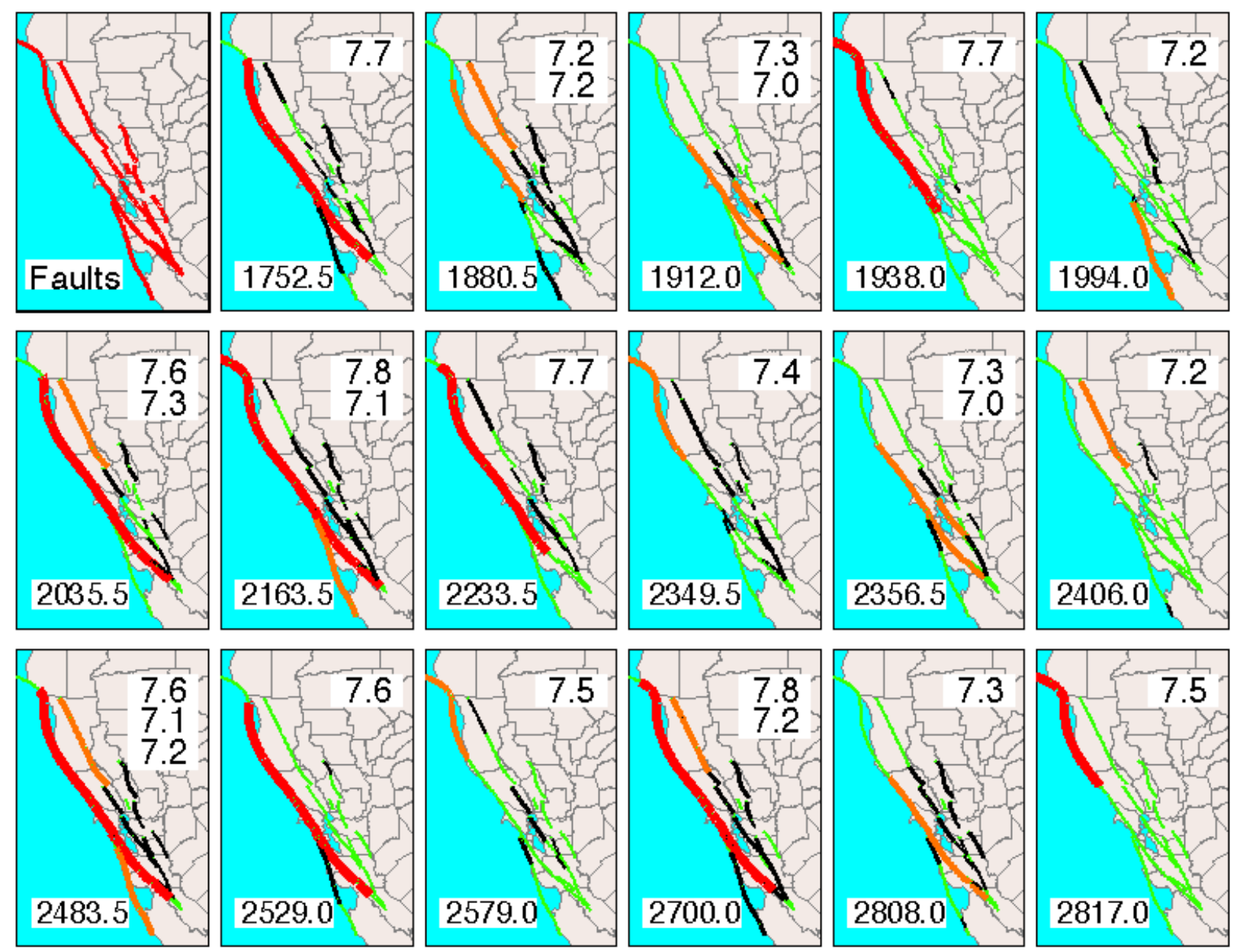

Figure 8.3 "Movie" continued. 


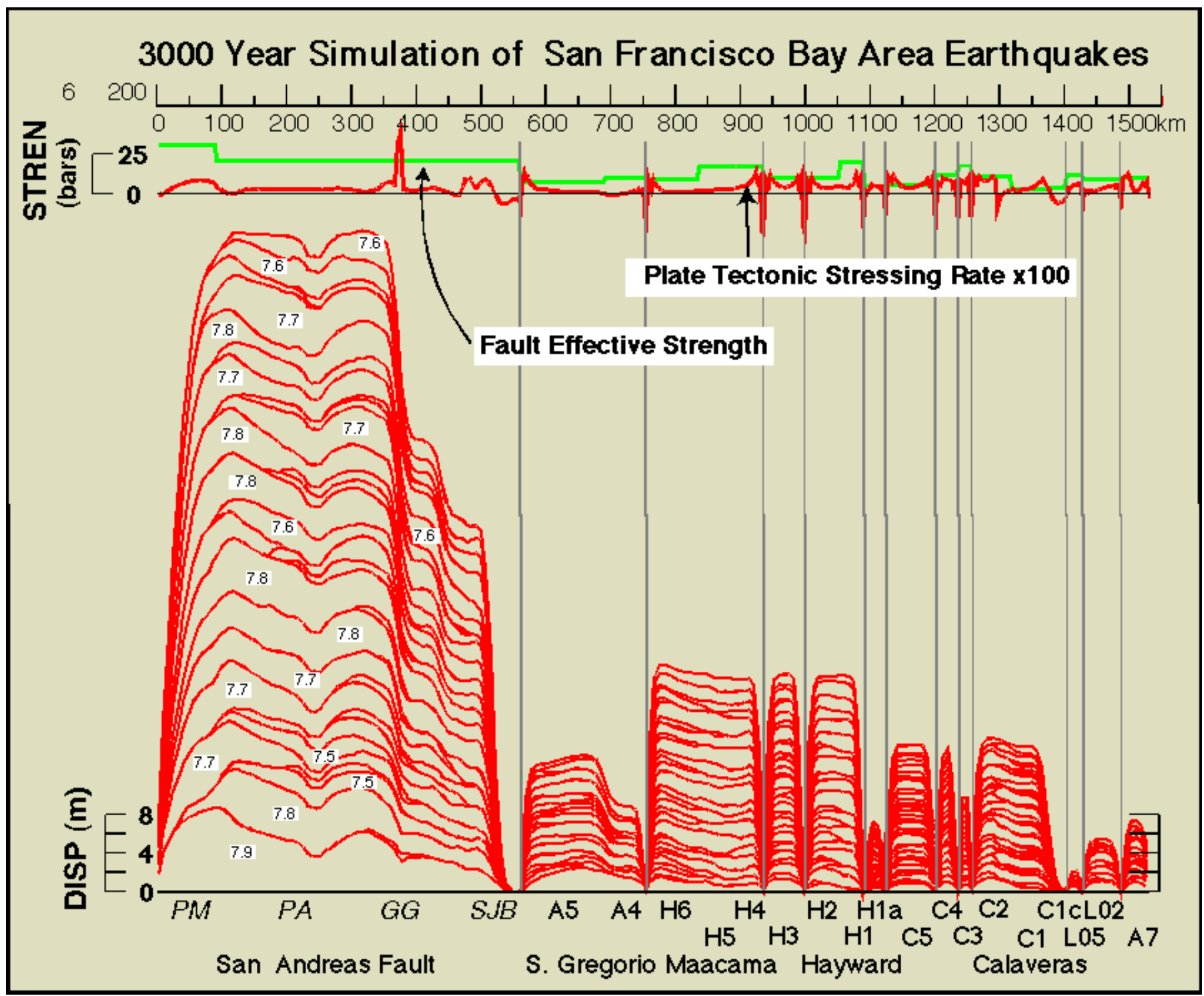

Figure 9. Seismic slip history for the 3000 year run of Bay Area synthetic seismicity. Each pillow represents the slip in one of the events in Figure 8. Magnitudes are listed for M7.5+ events. Gray line along the top traces the effective strength of the faults, $\Delta \mathbf{S}$. Black line along the top is the annual rate of tectonic loading, $\mathbf{T}_{\mathrm{p}} \mathrm{x} 100$. Witness the large peak in loading rate near the Golden Gate (GG) due to the right step there. 


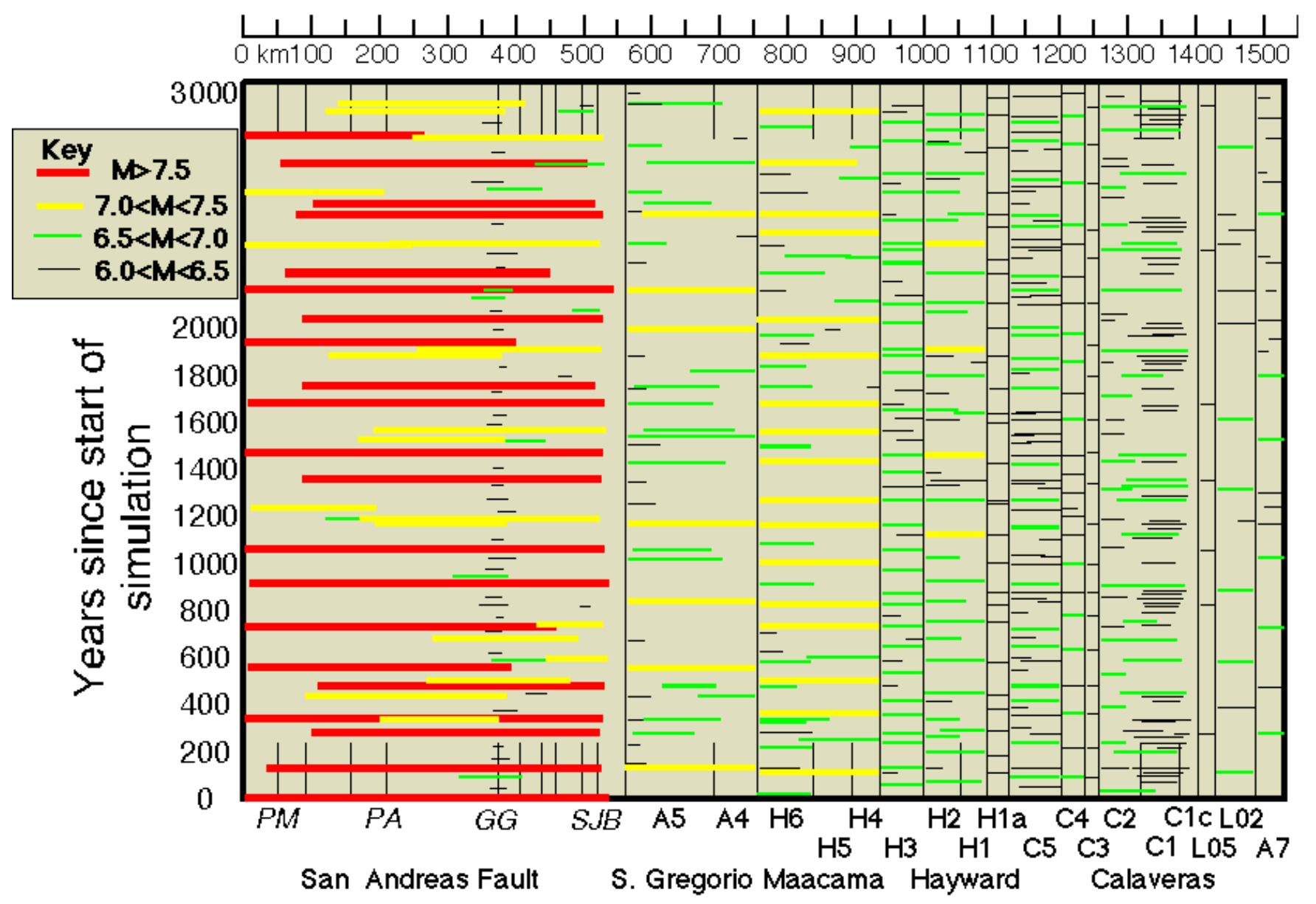

Figure 10. Space time seismicity plot for the San Francisco Bay Area covering a 3000 year span. Each horizontal line maps the position and time of a M6+ earthquake. Note the large number of M6 events generated near the Golden Gate (GG) due to the presence there of a $3 \mathrm{~km}$ right-step in the San Andreas Fault. 


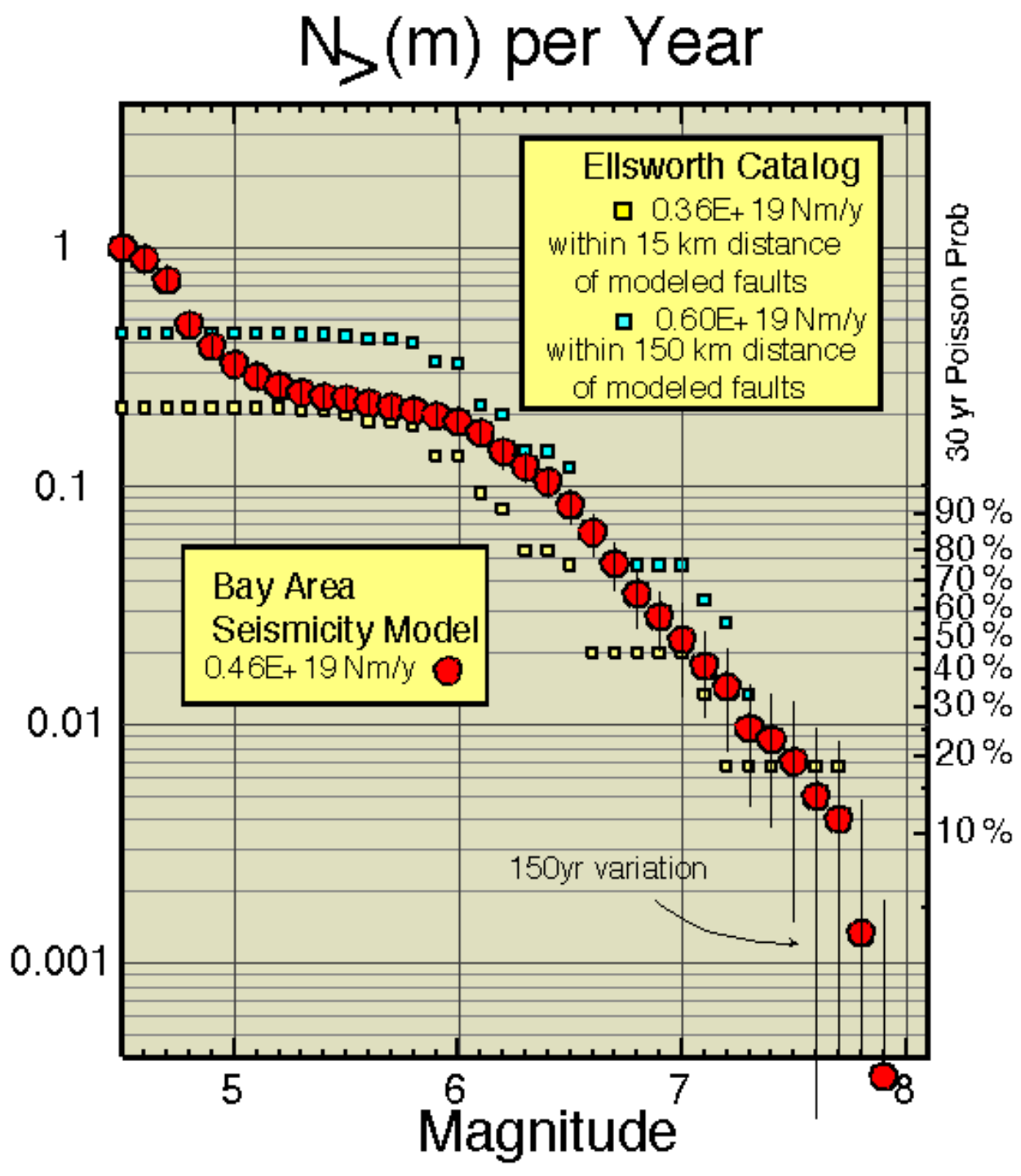

Figure 11. Annual rate of earthquakes greater than magnitude $M$ as produced by the simulation (circles) and the Ellsworth catalog (squares). The simulation reproduces the rates of observed earthquakes down to $M=6$, the point at which the Ellsworth catalog is no longer considered to be complete. The absence of many small unmodelled faults likely accounts for the tail-off in rates near $\mathrm{M}=5$. 


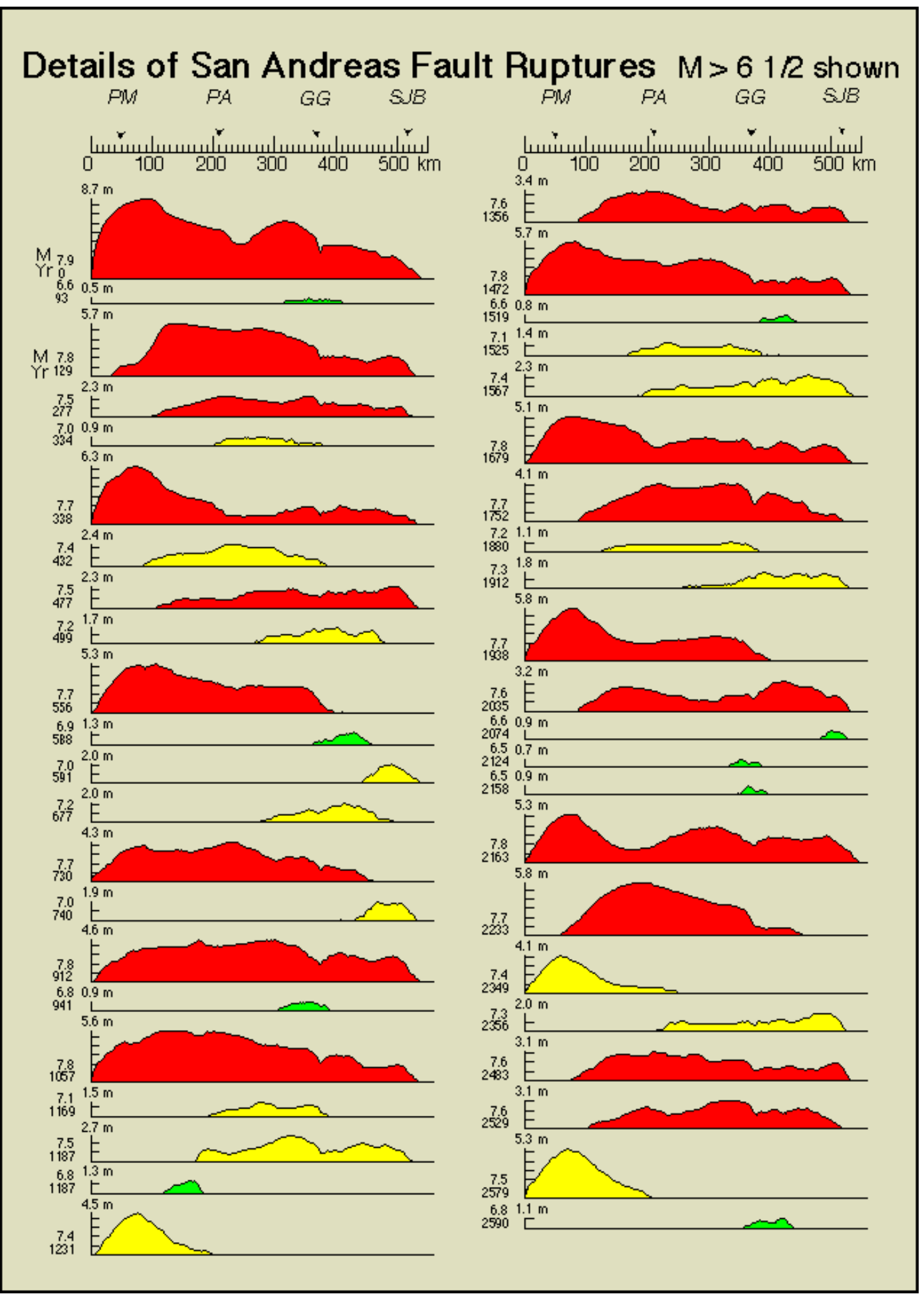

Figure 12. Details of the final slip distributions of all $M>6.5$ quakes on the San Andreas Fault for the first 2600 years of the 3000 year simulation. Magnitude and year of occurrence are listed to the left of each trace. Red, yellow and green events are $\mathrm{M}>7.5,7<\mathrm{M}<7.5$ and $6.5<\mathrm{M}<7$ respectively. Rupture encyclopedias like this can be compared directly with site-specific paleoseismic studies that quantify slip-per-event and variation in slip-perevent. 